Article

\title{
Investigation on Reference Frames and Time Systems in Multi-GNSS
}

\author{
Luca Nicolini and Alessandro Caporali * \\ Department of Geosciences, University of Padova, 35131 Padova, Italy; luca.ncln@gmail.com \\ * Correspondence: alessandro.caporali@unipd.it; Tel.: +39-049-827-9122
}

Received: 24 November 2017; Accepted: 3 January 2018; Published: 9 January 2018

\begin{abstract}
Receivers able to track satellites belonging to different GNSSs (Global Navigation Satellite Systems) are available on the market. To compute coordinates and velocities it is necessary to identify all the elements that contribute to interoperability of the different GNSSs. For example the timescales kept by different GNSSs have to be aligned. Receiver-specific biases, or firmware-dependent biases, need to be calibrated. The reference frame used in the representation of the orbits must be unique. In this paper we address the interoperability issues from the standpoint of a Single Point Positioning (SPP) user, i.e., using pseudoranges and broadcast ephemeris. The biases between GNSSs timescales and receiver-dependent biases are analyzed for a set of 31 MGEX (Multi-GNSS Experiment) stations over a time span of more than three years. Time series of biases between timescales of GPS (Global Positioning System), GLONASS (Global Navigation Satellite System), Galileo, BeiDou, QZSS (Quasi-Zenith Satellite System), SBAS (Satellite Based Augmentation System) and NAVIC (Navigation with Indian Constellation) are investigated, in addition to the identification of events like discontinuity of receiver-dependent biases due to firmware updating. The GPS broadcast reference frame is shown to be aligned to the one (IGS14) realized by the precise ephemeris of CODE (Center for Orbit Determination in Europe) to within $0.1 \mathrm{~m}$ and 2 milliarcsec, with values dependent on whether IIR-A, IIR-B/M or IIF satellite blocks are considered. Larger offsets are observed for GLONASS, up to $1 \mathrm{~m}$ for GLONASS K satellites. For Galileo the alignment of the broadcast orbit to IGS14/CODE is again at the $0.1 \mathrm{~m}$ and several milliarcsec level, with the FOC (Full Operational Capability) satellites slightly better than IOV (In Orbit Validation). For BeiDou an alignment of the broadcast frame to IGS14/CODE comparable to GLONASS is observed, regardless of whether IGSO (Inclined Geosynchronous Orbit) or MEO (Medium Earth Orbit) satellites are considered. For all satellites, position differences according to the broadcast ephemeris relative to IGS14/CODE orbits are projected to the radial, along-track and crosstrack triad, with the largest periodic differences affecting mostly the along track component. Sudden discontinuities at the level of up to $1 \mathrm{~m}$ and 2-3 ns are observed for the along-track component and the satellite clock, respectively. The time scales of GLONASS, Galileo, QZSS, SBAS and NAVIC are very closely aligned to GPS, with constant offsets depending on receiver type. The offset of the BeiDou time scale to GPS has an oscillatory pattern with peak-to-peak values up to $100 \mathrm{~ns}$. To characterize receiver-dependent biases the average of six Septentrio receivers is taken as reference, and relative offsets of the other receiver types are investigated. These receiver-dependent biases may depend on the individual station, or for the same station on the update of the firmware. A detailed calibration history is presented for each multiGNSS station studied.
\end{abstract}

Keywords: MGEX; multi-GNSS interoperability; Single Point Positioning; system time offsets; receiver dependent biases; temporal reference frames; spatial reference frames 


\section{Introduction}

As part of the contribution of the University of Padova to the MGEX program [1] and to the activities of the MultiGNSS Working Group within [2], 31 European GNSS sites have been monitored since 2014 with five different receivers (Javad, Leica, Septentrio, Topcon, Trimble). The location of the sites is shown in Figure 1 and the equipment at each site is described in Table 1. Three issues which are critical for the interoperability of the different GNSS constellations are considered from the user point of view:

- Alignment of the spatial reference frame implied by the broadcast orbits to a common frame aligned to ITRF (International Terrestrial Reference Frame), such as the one implied by the preciseephemeris of CODE (Center for Orbit Determination in Europe) at the University of Bern.

- Offset among the time scales of different GNSS constellations: are the reference time scale of the various GNSSs synchronized among each other?

- Do different receivers measure different offsets? Does the receiver dependent offset change subject e.g., to a firmware update?

GPS, GLONASS, Galileo and BeiDou are the systems taken into account. For some receivers at higher latitude (e.g., KIRU, Kiruna, Sweden; WROC, Wroclaw, Poland; NYA2, Ny Alesund, Svalbard; DLF1, Delft, The Netherlands; GANP, Ganovce, Slovak Republic) QZSS data are also available. A Septentrio receiver has also delivered data from the Indian NAVIC (formerly IRNSS) constellation. SBAS data are received from satellites S27 and S28, both belonging to the Indian overlay system GAGAN (GPS Aided Geo Augmented Navigation) in geostationary orbits. No data usable for positioning are available from other SBAS systems.

This paper is organized in two parts. In the first part, the offset between broadcast reference frames and ITRF has been evaluated, together with a comparison between broadcast and precise orbits and clocks. This part is described in Section 2. The second part of the paper focuses on the misalignment of the time scales adopted by GNSSs, and is described in Sections 3 and 4.

Montenbruck et al. [3] have carried out a similar analysis for the whole of 2013. In their study, they evaluate the signal-in-space ranging error (SISRE), which describes the error contributions due to broadcast orbits and clocks. They found that the GPS broadcast ephemerides show the best accuracy, with a RMS (Root Mean Square) orbit error of 0.18, 1.05 and $0.44 \mathrm{~m}$ in radial, along-track and cross-track directions respectively, and 2 ns as clock errors. For the other GNSS systems they found errors two to three times higher. The computed SISRE values confirm the better accuracy of GPS orbits compared to other GNSS's, since the global average SISRE values are $0.7 \pm 0.02 \mathrm{~m}$ (GPS), $1.5 \pm 0.1 \mathrm{~m}$ (BeiDou), $1.6 \pm 0.3 \mathrm{~m}$ (Galileo) and $1.9 \pm 0.1 \mathrm{~m}$ (GLONASS). These results apply to data available in 2013. Since then the quality of the signals and orbits have considerably improved, and a re-evaluation of the whole issue is justified.

MATLAB-based multiGNSS software (The MathWorks, Inc., Natick, MA, USA) is used for this purpose [4], which allows the estimation at each epoch of the three receiver coordinates, one Tropospheric Zenith Delay and $n_{\text {GNSS }}$ receiver time offsets, where $n_{\text {GNSS }}$ is the number of tracked GNSS constellations. The latter unknowns are the sums of the receiver clock offset and the offset of the GNSS time scale relative to a common, interGNSS time scale [5]. Differentiation of such an offset relative to the GPS data yields, epochwise and for each receiver, estimates of the GNSS time offset to GPS. Comparing across different receivers it can be seen that such offsets can be biased relative to each other by as much as several tens of nanoseconds. The average of six Septentrio receivers was arbitrarily selected as reference to estimate the receiver biases relative to the average Septentrio. For a given receiver brand, the bias relative to Septentrio for the various GNSS is very repeatable, with a few exceptions. It turns out that updating the firmware often affects the GNSS-dependent receiver bias. There are however examples of changes of the receiver-dependent bias which are uncorrelated with a firmware update. A table of "individual" calibrations, for each receiver and each GNSS time offset is presented. 
Table 1. List of stations included in the analysis.

\begin{tabular}{|c|c|c|c|c|c|c|}
\hline ID & City & Country & Domes & Receiver & Antenna & Start Date \\
\hline BBYS & Banka Bystrica & Slovak Republic & 11514M001 & Trimble NETR9 & TRM59800.00 & 1 January 2014 \\
\hline BOGO & Borowa Gora & Poland & 12207M002 & Topcon EUROCARD & ASH700936C_M & 21 June 2015 \\
\hline BRST & Brest & France & $10004 \mathrm{M} 004$ & Trimble NETR9 & TRM57971.00 & 1 January 2014 \\
\hline BRUX & Brussels & Belgium & $13101 \mathrm{M} 010$ & Septentrio POLARX4TR & JAVRINGANT_DM & 1 January 2014 \\
\hline CAEN & Caen & France & 19994M001 & Leica GR25 & TRM57971.00 & 1 January 2014 \\
\hline CEBR & Cebreros & Spain & $13408 \mathrm{M} 001$ & Septentrio POLARX4 & SEPCHOKE_MC & 1 January 2014 \\
\hline $\mathrm{COMO}$ & Como & Italy & $12761 \mathrm{M} 001$ & Topcon E_GGD & TPSCR3_GGD & 21 June 2015 \\
\hline $\mathrm{COMO}$ & Como & Italy & $12761 \mathrm{M} 001$ & Topcon NET-G5 & TPSCR3_GGD & 19 October 2016 \\
\hline $\mathrm{COMO}$ & Como & Italy & 12761M001 & Topcon NET-G5 & TPSCR.G3 & 7 February 2017 \\
\hline DLF1 & Delft & The Netherlands & 13502M009 & Trimble NETR9 & LEIAR25.R3 & 1 January 2014 \\
\hline DYNG & Dyonisos & Greece & $12602 \mathrm{M} 006$ & Trimble NETR9 & TRM59800.00 & 2 March 2015 \\
\hline GANP & Ganovce & Slovak Republic & $11515 \mathrm{M} 001$ & Trimble NETR9 & TRM55971.00 & 1 January 2014 \\
\hline GANP & Ganovce & Slovak Republic & $11515 \mathrm{M} 001$ & Trimble NETR9 & TRM59800.00 & 6 February 2017 \\
\hline GOP7 & Ondrejov & Slovak Republic & $11502 \mathrm{M} 006$ & Javad TRE_G3TH DELTA & LEIAR25.R4 & 1 January 2014 \\
\hline GOP7 & Ondrejov & Slovak Republic & $11502 \mathrm{M} 006$ & Trimble NETR9 & LEIAR25.R4 & 1 January 2014 \\
\hline HOFN & Hoefn & Iceland & 10204M002 & Leica GR25 & LEIAR25.R4 & 1 January 2014 \\
\hline IGMI & Firenze & Italy & $12701 \mathrm{M} 003$ & Topcon ODYSSEY_E & TPSCR.G3 & 21 June 2015 \\
\hline KIRU & Kiruna & Sweden & 10403M002 & Septentrio POLARX4 & SEPCHOKE_MC & 1 January 2014 \\
\hline MOSE & Roma & Italy & $12772 \mathrm{M} 001$ & Leica GR25 & LEIAR25.R4 & 1 January 2014 \\
\hline MAS1 & Maspalomas & Spain & 31303M002 & Septentrio POLARX4 & LEIAR25.R4 & 25 October 2015 \\
\hline MLVL & Marne-la-Vallee & France & 10092M001 & Leica GR25 & TRM57971.00 & 1 January 2014 \\
\hline NYA2 & Ny Alesund & Norway & 10317M008 & Javad TRE_G3TH DELTA & JAV_RINGANT_G3T & 25 October 2015 \\
\hline OBE4 & Oberpfaffenhofen & Germany & 14208M007 & Javad TRE_G3TH DELTA & JAV_RINGANT_G3T & 25 October 2015 \\
\hline PADO & Padova & Italy & $12750 S 001$ & Leica GR10 & LEIAR25.R4 & 1 January 2014 \\
\hline PEN2 & Penc & Hungary & $11206 \mathrm{M} 007$ & Leica GRX1200 + GNSS & LEIAR25.R4 & 2 March 2015 \\
\hline POTS & Potsdam & Germany & $14106 \mathrm{M} 003$ & Javad TRE_G3TH DELTA & JAV_RINGANT_G3T & 2 March 2015 \\
\hline REDU & Redu & Belgium & $13102 \mathrm{M} 001$ & Septentrio POLARX4 & SEPCHOKE_MC & 2 March 2015 \\
\hline REYK & Reykjavik & Iceland & $10202 \mathrm{M} 001$ & Leica GR25 & LEIAR25.R4 & 2 March 2015 \\
\hline SULP & Lviv & Ukraine & $12366 \mathrm{M} 001$ & Topcon NET-G3A & TPSCR.G5 & 21 June 2015 \\
\hline TLSE & Toulouse & France & 10003M009 & Trimble NETR9 & TRM59800.00 & 2 March 2015 \\
\hline VILL & Villafranca & Spain & 13406M001 & Septentrio POLARX4 & SEPCHOKE_MC & 25 October 2015 \\
\hline WROC & Wroclaw & Poland & 12217M001 & Leica GR25 & LEIAR25.R4 & 2 March 2015 \\
\hline WTZ3 & Bad Koetzting & Germany & 14201M015 & Javad TRE_G3TH DELTA & LEIAR25.R3 & 25 October 2015 \\
\hline WTZZ & Bad Koetzting & Germany & $14201 \mathrm{M} 014$ & Javad TRE_G3TH DELTA & LEIAR25.R3 & 1 January 2014 \\
\hline ZIMJ & Zimmerwald & Switzerland & $14001 \mathrm{M} 006$ & Javad TRE_G3TH DELTA & JAVRINGANT_DM & 1 January 2014 \\
\hline
\end{tabular}




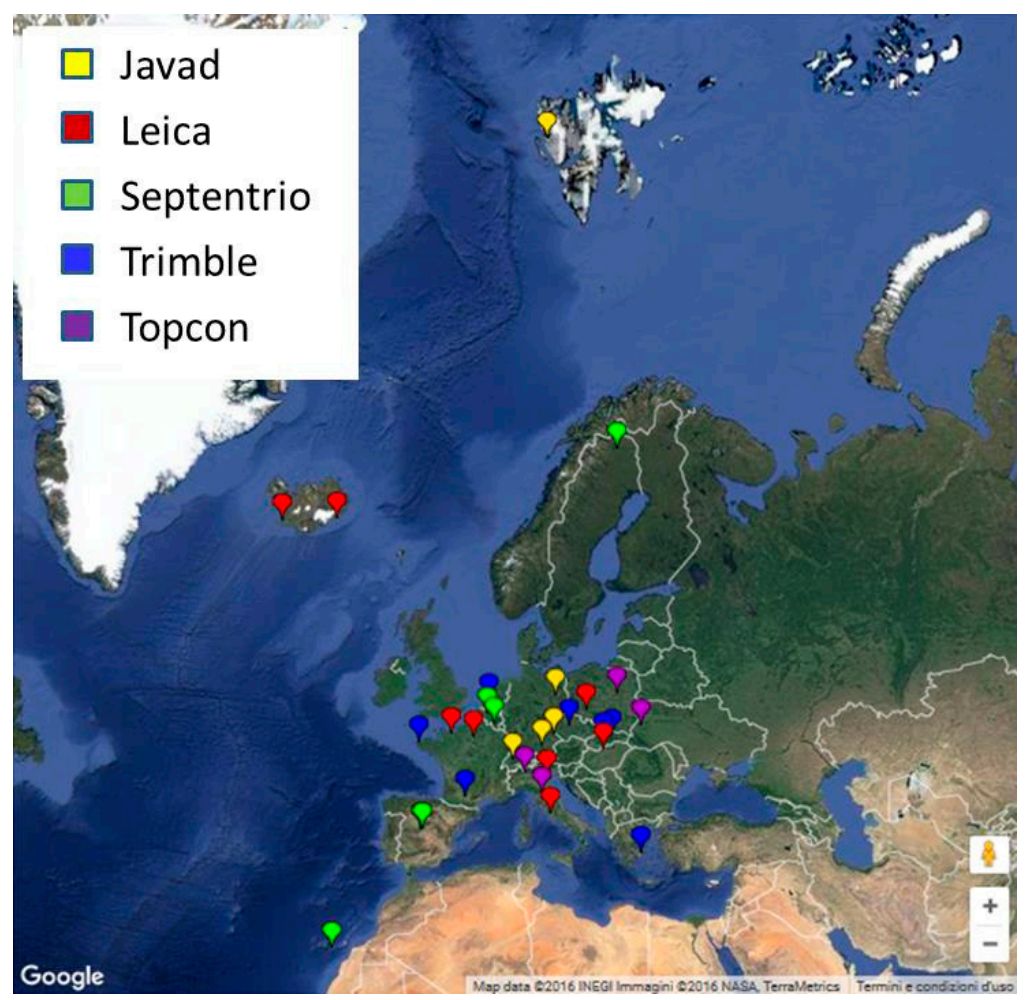

Figure 1. Map view of monitored sites.

\section{Quality Check of Broadcast Orbits}

To study the accuracy of the broadcast orbits relative to the precise orbits provided by CODE [6] SP3 (Extended Standard Product 3 Orbit Format), the alignment of the reference systems adopted by broadcast orbits with respect to that provided by precise orbits is analyzed. The reference frames adopted by the several GNSSs in the broadcast ephemeris are different from each other, namely WGS84 (GPS), PZ-90.11 (GLONASS), GTRF (Galileo) and CGCS2000 (BeiDou), whereas the reference frame adopted by precise orbits is typically unique. According to [7,8], current GLONASS broadcast ephemerides and all those since 31 December 2013 should be referred to PZ-90.11 as it is aligned to ITRF at millimeter level. The reference frame adopted by CODE during week 1950 is IGS14.

Broadcast and precise orbits are referred to different points of space vehicles: the antenna phase center (APC) and the center of mass (CoM), respectively. The relative distance of APC to CoM is the antenna phase offset (APO). Montenbruck et al. [3] decided not to apply any reference frame transformation in their comparative analysis. They inferred the APO from the comparison between broadcast and precise orbits except for BeiDou, for which they assumed that the broadcast ephemeris is referred to the CoM.

In this section the coordinate differences in the RSW (radial, along-track, cross-track) reference system (Figure 2) are also analyzed and computed on the post-fit residuals of the seven-parameter Helmert transformation [9] between broadcast and precise ephemeris, for each day and satellite of the four GNSSs: GPS, GLONASS, Galileo, BeiDou. To achieve this goal, the Bernese software [10] was used with a maximum threshold of $5 \mathrm{~m}$ as a condition for coordinate rejection. 


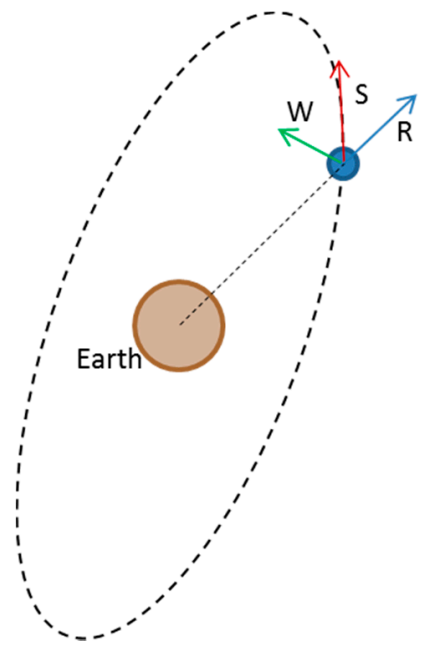

Figure 2. RSW reference system: radial (R), along-track (S) and cross-track (W).

\subsection{Comparison of Reference Systems}

The study focuses on GPS week 1950, i.e., from 21 May 2017 to 27 May 2017. For each day a set of Helmert parameters are obtained, which define the transformation from precise to broadcast reference systems, and consist of three translations $\left(T_{x}, T_{y}, T_{z}\right)$, three rotations $\left(R_{x}, R_{y}, R_{z}\right)$ and one scaling factor $(k)$ according to Equation (1).

$$
\left[\begin{array}{l}
x^{\prime} \\
y^{\prime} \\
z^{\prime}
\end{array}\right]=\left[\begin{array}{l}
T_{x} \\
T_{y} \\
T_{z}
\end{array}\right]+(1+k)\left[\begin{array}{ccc}
1 & R_{z} & -R_{y} \\
-R_{z} & 1 & R_{x} \\
R_{y} & -R_{x} & 1
\end{array}\right]\left[\begin{array}{l}
x \\
y \\
z
\end{array}\right]
$$

The weekly average values of each Helmert parameter has been computed. With these mean values the broadcast reference systems relative to precise reference system have been represented. Figures 3-6 show the rotations magnified in order to be visible (milliarcsecs are treated as degrees). The figure also contains a table with the sets of mean Helmert parameters and their standard deviation, for each block of satellites. Translations are measured in meters, rotations in milliarcsec and the scaling factor is expressed in $\mu \mathrm{m} / \mathrm{km}\left(1 \mu \mathrm{m}=10^{-6} \mathrm{~m}\right)$.

Precise orbits refer to CoM whereas broadcast orbits refer to APC. The relative distance between APC and CoM is the APO (Antenna Phase Offset). Among the three (x,y,z) APO components, the $\mathrm{z}$ component, which correspond to the boresight direction, is the prevalent one. Since APO is constant, the satellite orbits described by CoM and APC differ mainly by the constant offset given by the boresight component of APO, which is oriented in radial direction. So we assume that APO is absorbed by the scale factor of Helmert transformation.

For GPS and Galileo FOC (Full Operational Capability) satellites, the reference systems adopted by broadcast orbits are quite similar to those provided by precise orbits: the translation of the origin is less than $0.10 \mathrm{~m}$ and rotations are less than 2 milliarcsec. For Galileo IOV (In Orbit Validation), GLONASS and BeiDou higher differences are apparent. The Galileo IOV broadcast reference frame is offset to ITRF by at most $0.23 \pm 0.04 \mathrm{~m}$ in $\mathrm{Y}$ (Figure 5).

The GLONASS M broadcast reference frame is offset to ITRF by at most $0.27 \pm 0.05 \mathrm{~m}$ in $\mathrm{Y}$ and the maximum rotation is $4 \pm 2$ milliarcsec of arc about $Y$. The GLONASS K broadcast reference frame is offset to ITRF by at most $1.06 \pm 0.18 \mathrm{~m}$ in $\mathrm{Y}$ and the maximum rotation is $19 \pm 2$ milliarcsec about $\mathrm{X}$ (Figure 4).

The BeiDou IGSO broadcast reference frame is offset to ITRF by at most $0.31 \pm 0.08 \mathrm{~m}$ in $\mathrm{Y}$ and the maximum rotation is $3.6 \pm 2.0$ milliarcsec about $Z$ (Figure 6). For BeiDou MEO satellites we find Helmert parameters of the same order of magnitude of those found for IGSO satellites, but with a 
higher uncertainty. This margin of error is probably due to the limited number of available satellites (only three). The BeiDou MEO broadcast reference frame is offset to ITRF by at most $0.38 \pm 0.35 \mathrm{~m}$ in $\mathrm{X}$ and the maximum rotation is $4.3 \pm 2.9$ milliarcsec about $\mathrm{Z}$ (Figure 6).

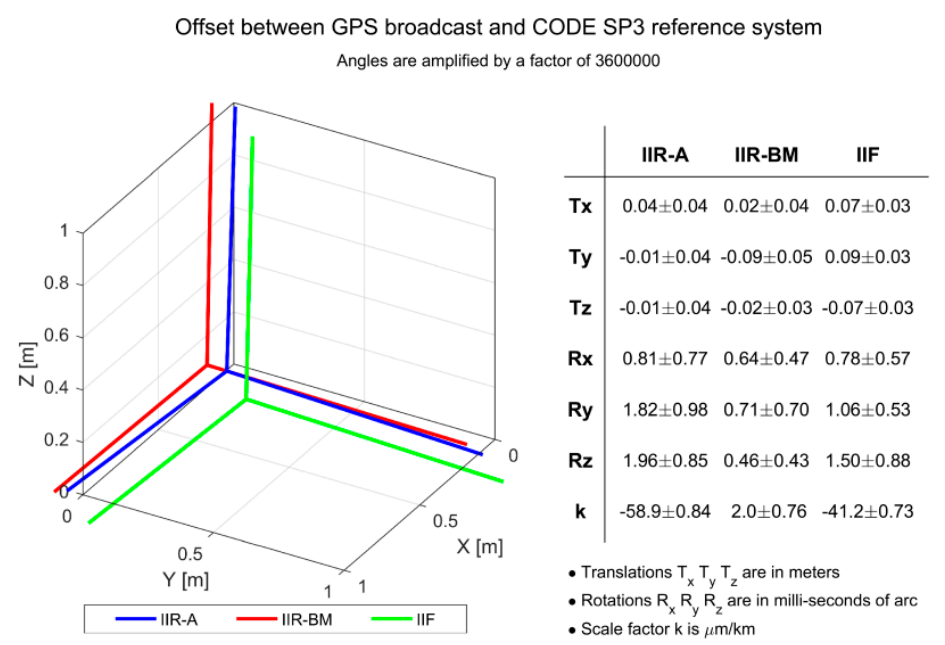

Figure 3. Representation of the offsets between the three GPS blocks (IIR-A, IIR-B/M, IIF) broadcast and precise reference system of CODE SP3.

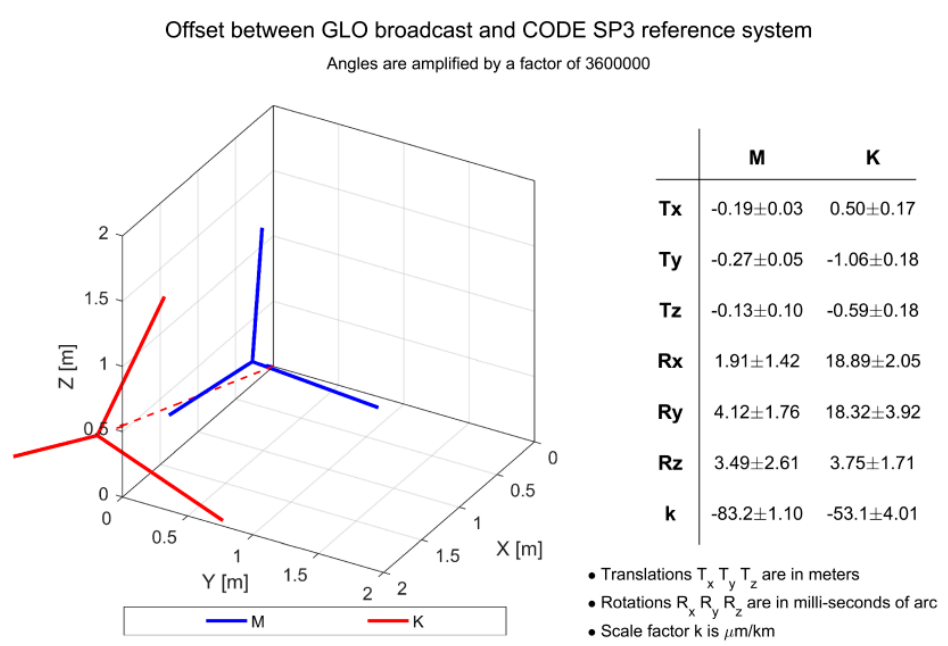

Figure 4. Representation of the offsets between the two GLONASS blocks (M, K) broadcast and precise reference system of CODE SP3. 


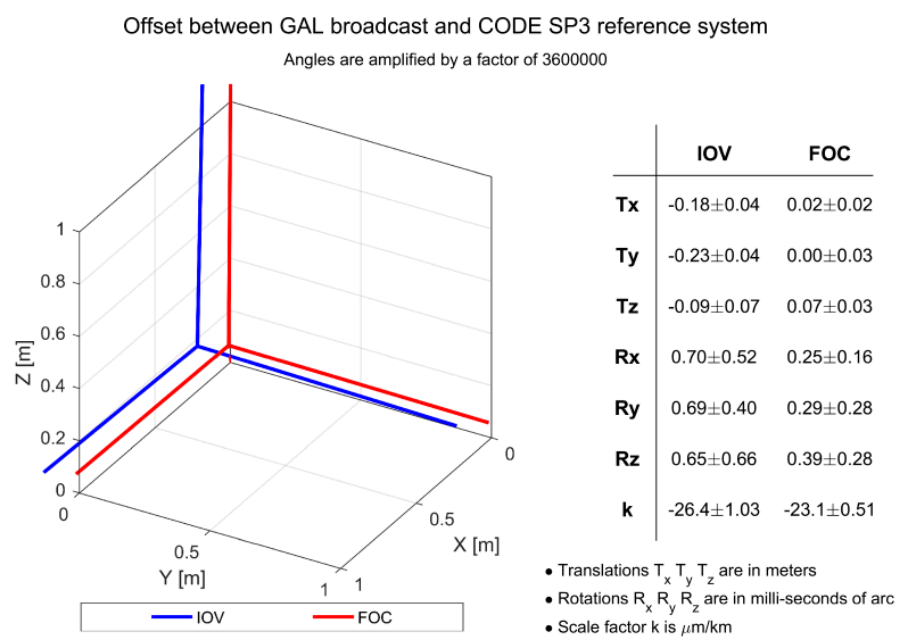

Figure 5. Representation of the offsets between Galileo (IOV, FOC) broadcast and precise reference system of CODE SP3.

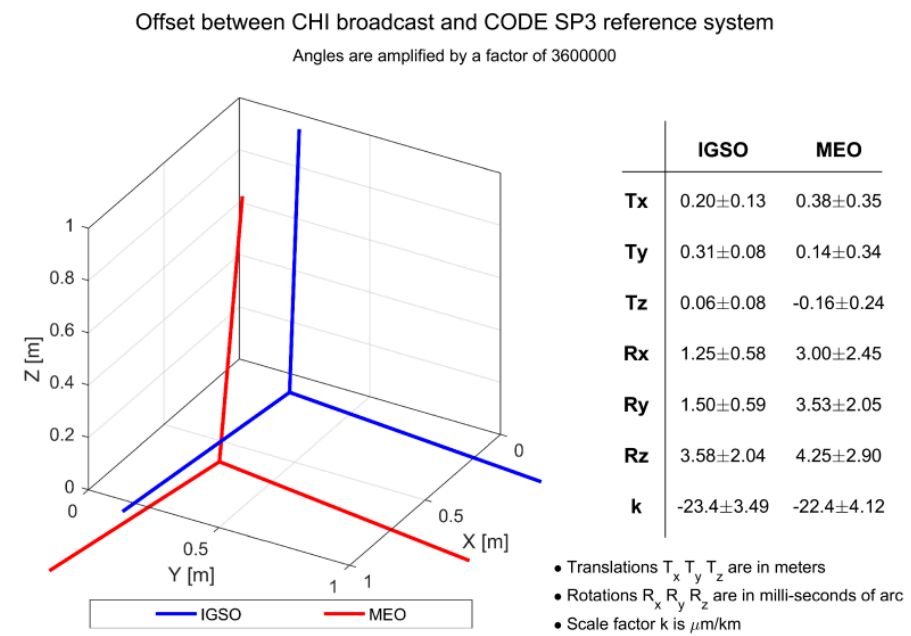

Figure 6. Representation of the offsets between BeiDou broadcast (IGSO, MEO) and precise reference system of CODE SP3.

\subsection{RSW Components of Coordinate Differences and Clock Differences}

Coordinate differences of broadcast vs. precise ephemeris of GPS are generally continuous. There are however occasional discontinuities, which affect mostly the along-track components. The coordinate differences in the radial and cross-track components may have an oscillatory pattern with a period of about $12 \mathrm{~h}$. The average values of standard deviations are $0.15,0.71,0.34 \mathrm{~m}$ and $1.1 \mathrm{~ns}$ for the radial, along-track, cross-track and clock component, respectively.

As to the satellite clocks, it is found that all satellites are equipped with atomic rubidium clocks, except G08 and G24, which are equipped with cesium atomic clocks and belong to block IIF. The average values of clock differences range between -3.4 and $2.0 \mathrm{~ns}$.

The magnitude of discontinuities is up to $0.3,1.5,0.2 \mathrm{~m}$ and $1 \mathrm{~ns}$ for the radial, along-track, out-of-plane and clock component, respectively. Mean values and standard deviations of coordinates and clock differences for each satellite are reported in Table 2. The complete time series of coordinates and clock differences for all GPS satellites are shown in Figure A1.

GLONASS coordinate and clock differences show an oscillating trend, with a period of about $12 \mathrm{~h}$, and discontinuities, which affect mostly the along-track and clock components. The average values of standard deviations are $0.48,1.35,0.74 \mathrm{~m}$ and $5.6 \mathrm{~ns}$ for the radial, along-track, cross-track and clock 
component, respectively. Average values of clock differences are different from one satellite to another, varying from -20 to $24 \mathrm{~ns}$. The magnitude of discontinuities is up to $0.3,3.0,0.3 \mathrm{~m}$ and $8 \mathrm{~ns}$ for the radial, along-track, out-of-plane and clock component, respectively.

Mean values and standard deviations of coordinates and clock differences for each satellite are reported in Table 3. The complete time series of coordinates and clock differences for all GLONASS satellites are shown in Figure A2.

BeiDou coordinate and clock differences show discontinuities, which affect mostly the along-track, especially for Medium Earth Orbit (MEO) satellites (C11, C12, C14), and clock components. Furthermore coordinate differences show an oscillating trend, with a period of about $12 \mathrm{~h}$ for MEO satellites and about a whole day for the other satellites (Inclined Geosynchronous Satellite Orbit-IGSO). The average values of standard deviations are $0.43,0.81,0.63 \mathrm{~m}$ and $2.3 \mathrm{~ns}$ for the radial, along-track, cross-track and clock component, respectively (except clock RMS of C11, for which a higher standard deviation is found, about $27 \mathrm{~ns}$, due to two large discontinuities). Average values of clock differences are different from one satellite to another, varying from 56 ns to $122 \mathrm{~ns}$. The magnitude of discontinuities is up to $0.3,1$ (IGSO) or 3 (MEO), $0.3 \mathrm{~m}$ and $5 \mathrm{~ns}$ for the radial, along-track, cross-track and clock component, respectively.

Table 2. GPS mean values and standard deviations of coordinates and clock differences.

\begin{tabular}{|c|c|c|c|c|c|c|}
\hline Satellite & Radial (m) & Along-Track (m) & Cross-Track (m) & Clock (ns) & Block & Clock $^{1}$ \\
\hline G01 & $0.00 \pm 0.12$ & $-0.09 \pm 0.44$ & $0.30 \pm 0.27$ & $-0.9 \pm 0.8$ & IIF & $\mathrm{Rb}$ \\
\hline G02 & $0.05 \pm 0.13$ & $-0.17 \pm 0.74$ & $0.08 \pm 0.50$ & $1.6 \pm 0.8$ & IIR-B & $\mathrm{Rb}$ \\
\hline G03 & $0.00 \pm 0.15$ & $-0.08 \pm 0.62$ & $0.27 \pm 0.35$ & $-2.4 \pm 0.8$ & IIF & $\mathrm{Rb}$ \\
\hline G05 & $0.00 \pm 0.10$ & $0.02 \pm 0.66$ & $0.19 \pm 0.25$ & $1.8 \pm 0.6$ & IIR-M & $\mathrm{Rb}$ \\
\hline G06 & $0.01 \pm 0.15$ & $-0.06 \pm 0.79$ & $0.28 \pm 0.34$ & $-0.3 \pm 0.5$ & IIF & $\mathrm{Rb}$ \\
\hline G07 & $-0.02 \pm 0.11$ & $-0.03 \pm 0.62$ & $0.00 \pm 0.38$ & $0.5 \pm 1.7$ & IIR-M & $\mathrm{Rb}$ \\
\hline G08 & $-0.02 \pm 0.29$ & $0.00 \pm 0.95$ & $-0.03 \pm 0.29$ & $-0.2 \pm 3.6$ & IIF & Cs \\
\hline G09 & $0.01 \pm 0.27$ & $0.04 \pm 0.42$ & $0.30 \pm 0.27$ & $0.0 \pm 0.8$ & IIF & $\mathrm{Rb}$ \\
\hline G10 & $-0.05 \pm 0.12$ & $0.25 \pm 0.67$ & $0.28 \pm 0.36$ & $-1.0 \pm 0.6$ & IIF & $\mathrm{Rb}$ \\
\hline G11 & $0.04 \pm 0.14$ & $0.36 \pm 0.43$ & $0.00 \pm 0.24$ & $-3.1 \pm 1.3$ & IIR-A & $\mathrm{Rb}$ \\
\hline G12 & $0.03 \pm 0.10$ & $0.32 \pm 0.93$ & $-0.07 \pm 0.28$ & $0.7 \pm 0.8$ & IIR-M & $\mathrm{Rb}$ \\
\hline G13 & $-0.02 \pm 0.13$ & $-0.11 \pm 0.57$ & $0.04 \pm 0.47$ & $-3.4 \pm 0.8$ & IIR-A & $\mathrm{Rb}$ \\
\hline G14 & $-0.04 \pm 0.13$ & $0.80 \pm 0.63$ & $0.04 \pm 0.52$ & $-2.3 \pm 0.5$ & IIR-A & $\mathrm{Rb}$ \\
\hline G15 & $-0.07 \pm 0.08$ & $0.72 \pm 1.06$ & $0.11 \pm 0.19$ & $0.7 \pm 0.7$ & IIR-M & $\mathrm{Rb}$ \\
\hline G16 & $-0.08 \pm 0.08$ & $-0.18 \pm 0.50$ & $-0.04 \pm 0.42$ & $-1.8 \pm 0.6$ & IIR-A & $\mathrm{Rb}$ \\
\hline G17 & $0.03 \pm 0.16$ & $0.74 \pm 1.12$ & $-0.05 \pm 0.31$ & $0.4 \pm 2.0$ & IIR-M & $\mathrm{Rb}$ \\
\hline G18 & $0.05 \pm 0.10$ & $-0.66 \pm 0.88$ & $0.14 \pm 0.32$ & $-2.1 \pm 1.3$ & IIR-A & $\mathrm{Rb}$ \\
\hline G19 & $-0.02 \pm 0.13$ & $0.50 \pm 0.77$ & $-0.06 \pm 0.54$ & $1.3 \pm 1.0$ & IIR-B & $\mathrm{Rb}$ \\
\hline G20 & $0.00 \pm 0.09$ & $-0.46 \pm 0.77$ & $0.13 \pm 0.27$ & $-2.0 \pm 0.9$ & IIR-A & $\mathrm{Rb}$ \\
\hline G21 & $-0.02 \pm 0.12$ & $0.02 \pm 0.82$ & $0.03 \pm 0.38$ & $-1.8 \pm 0.8$ & IIR-A & $\mathrm{Rb}$ \\
\hline G22 & $-0.11 \pm 0.10$ & $0.30 \pm 0.46$ & $0.20 \pm 0.46$ & $1.8 \pm 0.8$ & IIR-B & $\mathrm{Rb}$ \\
\hline G23 & $0.01 \pm 0.08$ & $-0.57 \pm 0.68$ & $0.13 \pm 0.44$ & $0.5 \pm 0.6$ & IIR-B & $\mathrm{Rb}$ \\
\hline G24 & $-0.01 \pm 0.42$ & $0.56 \pm 1.11$ & $-0.07 \pm 0.31$ & $-2.6 \pm 2.6$ & IIF & Cs \\
\hline G25 & $0.00 \pm 0.17$ & $0.22 \pm 0.62$ & $-0.17 \pm 0.37$ & $-1.3 \pm 0.8$ & IIF & $\mathrm{Rb}$ \\
\hline G26 & $0.03 \pm 0.21$ & $-0.47 \pm 0.64$ & $-0.13 \pm 0.26$ & $-0.5 \pm 0.5$ & IIF & $\mathrm{Rb}$ \\
\hline G27 & $-0.02 \pm 0.30$ & $0.08 \pm 0.68$ & $-0.02 \pm 0.24$ & $-0.9 \pm 0.7$ & IIF & $\mathrm{Rb}$ \\
\hline G28 & $0.08 \pm 0.13$ & $-0.12 \pm 0.61$ & $-0.02 \pm 0.18$ & $-2.6 \pm 3.9$ & IIR-A & $\mathrm{Rb}$ \\
\hline G29 & $0.06 \pm 0.12$ & $-0.92 \pm 0.74$ & $-0.07 \pm 0.45$ & $2.0 \pm 1.0$ & IIR-M & $\mathrm{Rb}$ \\
\hline G30 & $0.03 \pm 0.22$ & $-0.23 \pm 0.53$ & $-0.09 \pm 0.25$ & $-0.8 \pm 0.8$ & IIF & $\mathrm{Rb}$ \\
\hline G31 & $0.04 \pm 0.13$ & $-0.25 \pm 0.81$ & $0.00 \pm 0.29$ & $0.8 \pm 0.8$ & IIR-M & $\mathrm{Rb}$ \\
\hline G32 & $0.01 \pm 0.19$ & $-0.21 \pm 0.70$ & $0.29 \pm 0.31$ & $-0.6 \pm 0.6$ & IIF & $\mathrm{Rb}$ \\
\hline
\end{tabular}

${ }^{1}$ Rb: Rubidium, Cs: Cesium. 
Table 3. GLONASS mean values and standard deviations of coordinates and clock differences.

\begin{tabular}{ccccccc}
\hline Satellite & Radial $(\mathbf{m})$ & Along-Track $(\mathbf{m})$ & Cross-Track $(\mathbf{m})$ & Clock $(\mathbf{n s})$ & Block & Clock $^{\mathbf{1}}$ \\
\hline R01 & $0.10 \pm 0.41$ & $-0.42 \pm 0.70$ & $-0.19 \pm 0.62$ & $-2.4 \pm 3.0$ & $\mathrm{M}$ & $\mathrm{Cs}$ \\
R02 & $0.07 \pm 0.44$ & $-0.03 \pm 1.13$ & $-0.14 \pm 0.67$ & $-6.1 \pm 5.8$ & $\mathrm{M}$ & $\mathrm{Cs}$ \\
R03 & $0.08 \pm 0.40$ & $0.78 \pm 0.87$ & $-0.12 \pm 0.97$ & $20.1 \pm 6.0$ & $\mathrm{M}$ & $\mathrm{Cs}$ \\
R04 & $0.08 \pm 0.41$ & $-0.72 \pm 1.10$ & $-0.16 \pm 0.45$ & $22.2 \pm 6.3$ & $\mathrm{M}$ & $\mathrm{Cs}$ \\
R05 & $0.08 \pm 0.39$ & $1.22 \pm 1.58$ & $-0.18 \pm 0.90$ & $-1.5 \pm 5.8$ & $\mathrm{M}$ & $\mathrm{Cs}$ \\
R06 & $0.16 \pm 0.47$ & $0.79 \pm 1.72$ & $-0.17 \pm 0.54$ & $0.1 \pm 5.9$ & $\mathrm{M}$ & $\mathrm{Cs}$ \\
R07 & $0.14 \pm 0.38$ & $0.46 \pm 1.01$ & $-0.12 \pm 0.62$ & $14.6 \pm 4.3$ & $\mathrm{M}$ & $\mathrm{Cs}$ \\
R08 & $0.12 \pm 0.41$ & $-0.41 \pm 1.15$ & $-0.15 \pm 0.97$ & $24.3 \pm 4.4$ & $\mathrm{M}$ & $\mathrm{Cs}$ \\
R09 & $0.00 \pm 0.58$ & $0.00 \pm 0.79$ & $0.00 \pm 0.36$ & $10.3 \pm 3.9$ & $\mathrm{~K}$ & $\mathrm{Cs}$ \\
R10 & $-0.29 \pm 0.49$ & $-0.21 \pm 0.73$ & $0.18 \pm 1.06$ & $-13.9 \pm 7.2$ & $\mathrm{M}$ & $\mathrm{Cs}$ \\
R11 & $0.05 \pm 0.42$ & $1.91 \pm 0.89$ & $0.18 \pm 0.65$ & $6.4 \pm 5.3$ & $\mathrm{M}$ & $\mathrm{Cs}$ \\
R13 & $0.08 \pm 0.46$ & $-0.31 \pm 2.35$ & $0.15 \pm 0.73$ & $-3.1 \pm 4.7$ & $\mathrm{M}$ & $\mathrm{Cs}$ \\
R14 & $-0.30 \pm 0.46$ & $-0.23 \pm 2.94$ & $0.14 \pm 0.93$ & $-20.2 \pm 9.7$ & $\mathrm{M}$ & $\mathrm{Cs}$ \\
R15 & $-0.30 \pm 0.49$ & $-1.13 \pm 2.32$ & $0.09 \pm 0.99$ & $0.6 \pm 9.9$ & $\mathrm{M}$ & $\mathrm{Cs}$ \\
R16 & $-0.01 \pm 0.44$ & $1.31 \pm 1.12$ & $0.09 \pm 0.69$ & $3.7 \pm 5.2$ & $\mathrm{M}$ & $\mathrm{Cs}$ \\
R17 & $0.03 \pm 0.62$ & $2.31 \pm 0.88$ & $-0.13 \pm 0.74$ & $11.8 \pm 5.0$ & $\mathrm{M}$ & $\mathrm{Cs}$ \\
R18 & $-0.01 \pm 0.48$ & $0.31 \pm 0.87$ & $-0.15 \pm 0.76$ & $-4.6 \pm 4.3$ & $\mathrm{M}$ & $\mathrm{Cs}$ \\
R19 & $0.06 \pm 0.66$ & $1.06 \pm 2.00$ & $-0.09 \pm 0.78$ & $6.9 \pm 5.9$ & $\mathrm{M}$ & $\mathrm{Cs}$ \\
R20 & $-0.35 \pm 0.64$ & $0.01 \pm 2.19$ & $-0.11 \pm 0.71$ & $5.1 \pm 4.8$ & $\mathrm{M}$ & $\mathrm{Cs}$ \\
R21 & $0.02 \pm 0.53$ & $0.35 \pm 0.82$ & $-0.08 \pm 0.66$ & $13.1 \pm 4.7$ & $\mathrm{M}$ & $\mathrm{Cs}$ \\
R22 & $0.03 \pm 0.46$ & $-1.17 \pm 1.87$ & $-0.07 \pm 0.72$ & $0.0 \pm 7.5$ & $\mathrm{M}$ & $\mathrm{Cs}$ \\
R23 & $-0.05 \pm 0.52$ & $1.78 \pm 0.97$ & $-0.08 \pm 0.67$ & $2.2 \pm 4.7$ & $\mathrm{M}$ & $\mathrm{Cs}$ \\
R24 & $0.18 \pm 0.57$ & $-0.96 \pm 1.02$ & $-0.09 \pm 0.79$ & $6.2 \pm 3.5$ & $\mathrm{M}$ & $\mathrm{Cs}$ \\
\hline
\end{tabular}

Mean values and standard deviations of coordinates and clock differences for each satellite are reported in Table 4. The complete time series of coordinates and clock differences for all BeiDou satellites are shown in Figure A3.

For Galileo, it is important to remember that three types of ephemeris are available: I/NAV E1-B, F/NAV E5a and I/NAV E5b. I/NAV E1-B ephemeris has been chosen because this type of ephemeris is updated more frequently in the timeframe considered. Referring to Galileo ICD (Interface Control Document) [11], I/NAV blocks with Health Status equal to 1 (Signal out of service) have been rejected and others accepted. Of the 17 satellites, 11 are found to have a SV health value of 0 , which means Data Validity Status = "Navigation Data Valid" and Health status = "Signal OK". For the other six satellites the same value is 455, which means Data Validity Status = "Working without guarantee" and Health status = "Signal Component currently in Test". These satellites are the last four launched on 17 November 2016 (E03, E04, E05, E07) and the two launched on 22 August 2014 (E14, E18) into non nominal elliptical orbit [12]. The week analyzed is later than the epochs of orbit circularization, which were concluded in December 2014 and March 2015, respectively.

Table 4. BeiDou mean values and standard deviations of coordinates and clock differences.

\begin{tabular}{ccccccc}
\hline Satellite & Radial $(\mathbf{m})$ & Along-Track $(\mathbf{m})$ & Cross-Track $(\mathbf{m})$ & Clock $(\mathbf{n s})$ & Orbit & Clock $^{3}$ \\
\hline C06 & $-1.15 \pm 0.31$ & $0.14 \pm 0.51$ & $-0.01 \pm 0.59$ & $104.8 \pm 2.2$ & IGSO $^{1}$ & $\mathrm{Rb}$ \\
C07 & $0.99 \pm 0.35$ & $-0.03 \pm 0.60$ & $-0.21 \pm 0.44$ & $121.5 \pm 2.0$ & IGSO $^{1}$ & $\mathrm{Rb}$ \\
C08 & $0.31 \pm 0.48$ & $0.51 \pm 0.39$ & $0.09 \pm 0.86$ & $113.6 \pm 2.4$ & IGSO $^{1}$ & $\mathrm{Rb}$ \\
C09 & $-0.28 \pm 0.30$ & $-0.32 \pm 0.43$ & $-0.13 \pm 0.77$ & $94.8 \pm 2.0$ & IGSO $^{1}$ & $\mathrm{Rb}$ \\
C10 & $-0.14 \pm 0.32$ & $0.39 \pm 0.70$ & $-0.07 \pm 0.46$ & $95.5 \pm 2.3$ & IGSO $^{1}$ & $\mathrm{Rb}$ \\
C11 & $-0.39 \pm 0.55$ & $-0.20 \pm 1.26$ & $0.04 \pm 0.64$ & $88.4 \pm 27.2$ & MEO $^{2}$ & $\mathrm{Rb}$ \\
C12 & $-0.03 \pm 0.49$ & $0.02 \pm 1.33$ & $0.02 \pm 0.54$ & $93.1 \pm 2.5$ & MEO $^{2}$ & $\mathrm{Rb}$ \\
C13 & $0.26 \pm 0.63$ & $-0.22 \pm 0.61$ & $-0.03 \pm 0.81$ & $55.8 \pm 1.6$ & IGSO $^{1}$ & $\mathrm{Rb}$ \\
C14 & $0.43 \pm 0.45$ & $-0.53 \pm 1.48$ & $0.50 \pm 0.59$ & $99.9 \pm 3.1$ & MEO $^{2}$ & $\mathrm{Rb}$ \\
\hline
\end{tabular}

\footnotetext{
${ }^{1}$ Inclined Geosynchronous Orbit; ${ }^{2}$ Medium Earth Orbit; ${ }^{3}$ Rb: Rubidium.
} 
For Galileo, gaps have been found in the spacing between I/NAV ephemeris blocks larger than the validity period of the ephemeris block, i.e., \pm 3600 s. This prevents the computation of satellite coordinates and clock in the gaps. The availability of broadcast ephemeris is shown in Figure 7, where each block of healthy ephemeris is plotted with a circular black marker and each block of unhealthy ephemeris is plotted with a cross-shaped gray marker. In the studied days all the ephemeris blocks were set to healthy. In the periods of continuity of validity of ephemeris, it is possible to notice discontinuities in satellite coordinates (mostly in the along-track component) and clock.

For Galileo, the coordinate differences show an oscillating trend with a period of about $12 \mathrm{~h}$. The average values of standard deviations are $0.14,0.29,0.16 \mathrm{~m}$ and $1.3 \mathrm{~ns}$ for the radial, along-track, cross-track and clock component, respectively. The average values of clock differences range between 0.7 and $7.8 \mathrm{~ns}$. The magnitude of discontinuities is up to $0.2,1.0,0.3 \mathrm{~m}$ and $2 \mathrm{~ns}$ for the radial, along-track, cross-track and clock component, respectively.

E14 and E18 show scattered coordinate differences with very large ( $>5 \mathrm{~m}$ ) values, so about $75 \%$ of coordinates are rejected by Bernese and not considered in the estimating of Helmert parameters. Their clock differences show an offset of about 4-8 ns, with the same standard deviation of the other satellites.

Mean values and standard deviations of coordinates and clock differences for each satellite are reported in Table 5. The coordinate and clock accuracy of In-Orbit Validation (IOV) satellites is consistent with that of the Full Operational Capability (FOC) satellites. Both generations of satellites are equipped with passive hydrogen maser (PHM) clocks. The complete time series of coordinates and clock differences for all Galileo satellites are shown in Figure A4.

GAL broadcast ephemeris availability 213/2017 - Message Type: I/NAV E1-B

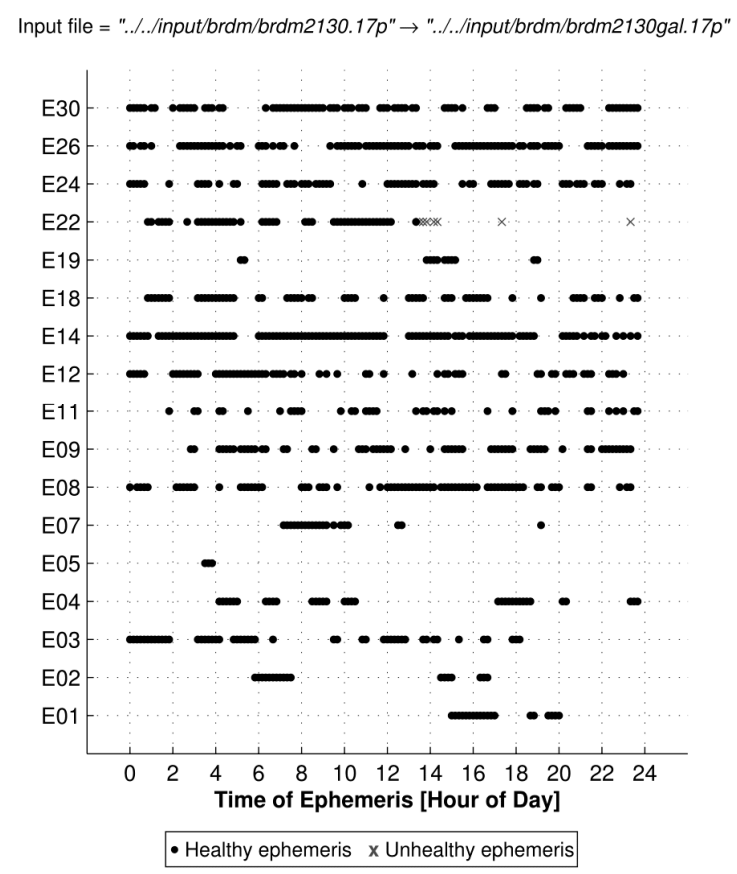

Figure 7. Availability of Galileo I/NAV-E1-B broadcast ephemeris on day 1 August 2017. 
Table 5. Galileo mean values and standard deviations of coordinates and clock differences.

\begin{tabular}{ccccccc}
\hline Satellite & Radial $(\mathbf{m})$ & Along-Track $(\mathbf{m})$ & Cross-Track $(\mathbf{m})$ & Clock $(\mathbf{n s})$ & Generation & Clock $^{3}$ \\
\hline E01 & $0.01 \pm 0.14$ & $-0.13 \pm 0.28$ & $-0.04 \pm 0.16$ & $2.2 \pm 1.3$ & FOC $^{2}$ & PHM \\
E02 & $-0.01 \pm 0.15$ & $-0.06 \pm 0.29$ & $0.04 \pm 0.13$ & $1.3 \pm 1.1$ & FOC $^{2}$ & PHM \\
E03 & $0.01 \pm 0.11$ & $-0.10 \pm 0.25$ & $0.00 \pm 0.17$ & $2.1 \pm 1.2$ & FOC $^{2}$ & PHM \\
E04 & $-0.01 \pm 0.11$ & $-0.05 \pm 0.36$ & $0.01 \pm 0.16$ & $1.6 \pm 1.2$ & FOC $^{2}$ & PHM \\
E05 & $-0.03 \pm 0.12$ & $0.00 \pm 0.25$ & $0.01 \pm 0.16$ & $2.1 \pm 1.1$ & FOC $^{2}$ & PHM \\
E07 & $0.01 \pm 0.12$ & $-0.11 \pm 0.28$ & $0.05 \pm 0.16$ & $2.8 \pm 1.3$ & FOC $^{2}$ & PHM \\
E08 & $-0.01 \pm 0.11$ & $0.04 \pm 0.24$ & $0.04 \pm 0.14$ & $1.0 \pm 1.2$ & FOC $^{2}$ & PHM \\
E09 & $0.00 \pm 0.13$ & $0.05 \pm 0.30$ & $0.03 \pm 0.17$ & $1.7 \pm 1.2$ & FOC $^{2}$ & PHM \\
E11 & $0.01 \pm 0.15$ & $0.00 \pm 0.35$ & $-0.05 \pm 0.18$ & $0.7 \pm 1.2$ & IOV $^{1}$ & PHM \\
E12 & $0.00 \pm 0.13$ & $-0.04 \pm 0.31$ & $-0.04 \pm 0.17$ & $1.6 \pm 1.4$ & IOV $^{1}$ & PHM \\
E14 & $0.04 \pm 0.48$ & $0.04 \pm 2.10$ & $-0.14 \pm 0.84$ & $6.7 \pm 1.3$ & FOC $^{2}$ & PHM \\
E18 & $0.04 \pm 0.37$ & $-0.04 \pm 2.05$ & $-0.02 \pm 0.50$ & $4.1 \pm 1.2$ & FOC $^{2}$ & PHM \\
E19 & $-0.01 \pm 0.18$ & $-0.08 \pm 0.44$ & $-0.01 \pm 0.23$ & $1.1 \pm 1.5$ & IOV $^{1}$ & PHM \\
E22 & $-0.01 \pm 0.16$ & $0.03 \pm 0.25$ & $-0.05 \pm 0.13$ & $1.4 \pm 1.5$ & FOC $^{2}$ & PHM \\
E24 & $-0.02 \pm 0.15$ & $0.01 \pm 0.25$ & $-0.05 \pm 0.17$ & $7.8 \pm 1.1$ & FOC $^{2}$ & PHM \\
E26 & $0.01 \pm 0.16$ & $-0.09 \pm 0.29$ & $-0.06 \pm 0.15$ & $2.5 \pm 1.3$ & FOC & PHM \\
E30 & $0.02 \pm 0.15$ & $-0.02 \pm 0.22$ & $0.02 \pm 0.16$ & $2.0 \pm 1.2$ & FOC & PHM \\
\hline
\end{tabular}

${ }^{1}$ In-Orbit Validation; ${ }^{2}$ Full Operational Capability; ${ }^{3}$ PHM: Passive Hydrogen Maser.

\section{Data Used and Adopted Model of the Pseudorange}

RINEX (Receiver Independent Exchange Format) 3.x [13] observation data was used for all receivers except Topcon, for which the provided RINEX 2.x files are converted to RINEX 3.x with the utility gfzrnx of the German Research Centre for Geosciences (GFZ) [14]. As to the orbits, satellite clocks and other ancillary data (e.g., quality flags), broadcast ephemeris in RINEX format downloaded from the MGEX FTP servers was used [1].

Several codes are available in the carriers at several frequencies, for the different GNSS constellations. The well-known "iono-free" linear combination of dual frequency code observations was used in order to remove first order ionospheric delay [9]. Table 6 summarizes the GNSS specific frequency bands and observation codes. The GPS broadcast clock model refers to iono-free combination of precise codes, i.e., $\mathrm{C} 1 \mathrm{~W}-\mathrm{C} 2 \mathrm{~W}$. We decided to analyze the combination $\mathrm{C} 1 \mathrm{C}-\mathrm{C} 2 \mathrm{~W}$ because about half of the stations (more precisely all the Leica and Trimble stations) do not track C1W. The error introduced using C1C in place of C1W depends on GPS satellite and varies between about -1 and 1 $\mathrm{m}$. This means about \pm 3 nanoseconds which is within the accepted tolerance. For GLONASS, the $\mathrm{k}$ factor varies from -7 to +6 according to the satellite [15]: such information is provided in the header of the observation RINEX file. For Galileo the I/NAV combination of codes and the related navigation message is used [11].

The model of the pseudorange $p(t)$ is described in Equations (2)-(6). In Equation (2) the effect of the Differential Code Bias (DCB) as listed in files provided by CODE has been ignored. For GPS the DCBs are up \pm 2 nanoseconds which is within our error budget. For GLONASS the DCBs are station-dependent and the estimates are provided only for a small subset of stations, for the other constellations no DCBs are provided (ftp://igs.bkg.bund.de/IGS/products/mgex/). Table 7 contains the explanation of the variables. The matrix of partial derivatives is shown in Equation (7), where seven GNSS are considered: GPS, GLONASS, Galileo, BeiDou, QZSS, NAVIC and GAGAN. The term ]$\rho$ indicates the geometric range between satellite and receiver.

In Equation (8) $y$ is defined as the column vector of observed minus computed: each element of $y$ is the difference between iono-free linear combination of pseudoranges and the right side of Equation (2). The number of elements of $y$ is equal to the number of satellites in view.

The column vector of the solution, denoted as $x$, is the solution of the normal equations expressed by Equation (8). The vector $x$ consists of three coordinates, $\mathrm{n}$ terms $T S C_{X}+d T_{R e c}$, where $\mathrm{n}$ is the number of GNSS's considered, and one TZD (Tropospheric Zenith Delay). The explicit form of the 
solution is given in Equation (9). Term TSC $_{X}$ is a GNSS-specific Time System Correction, which is dependent on the GNSS but independent of the receiver. Term $d T_{R e c}$ is the receiver clock offset, which is independent of the GNSS. However we will see later that different receivers measure different $T S C_{X}$ implying receiver biases which are dependent both on the receiver and the GNSS [16]. To monitor the GNSS specific time offset it is convenient to take $T S C_{G}$ as the reference time scale and evaluate the difference $\left(T S C_{X}+d T_{R e c}\right)-\left(T S C_{G}+d T_{R e c}\right)$, with $\mathrm{X}$ referring to all the GNSS's different from GPS [17]. In such a way we obtain the sum of the system specific time offset relative to GPS and the receiver hardware inter-system bias (ISB) [17-19]. Table 8 lists these specific variables.

$$
\begin{aligned}
& p(t)=\varrho-c \cdot d t\left(t^{\prime}\right)+c \cdot\left(T S C_{X}+d T_{R e c}\right)+\frac{T Z D}{\sin (E l)} \\
& \varrho \varrho=\sqrt{\left[X\left(t^{\prime}\right)+Y\left(t^{\prime}\right) \cdot \omega_{e} \cdot t_{o f}-x\right]^{2}+\left[Y\left(t^{\prime}\right)-X\left(t^{\prime}\right) \cdot \omega_{e} \cdot t_{o f}-y\right]^{2}+\left[Z\left(t^{\prime}\right)-z\right]^{2}} \\
& d t\left(t^{\prime}\right)=a_{0}+a_{1} \cdot\left(t^{\prime}-T_{o c}-L S\right)+a_{2} \cdot\left(t^{\prime}-T_{o c}-L S\right)^{2}+d T_{R e l} \\
& d T_{\text {Rel }}=-\frac{2 \cdot(\bar{X} \cdot \bar{v})}{c^{2}} \\
& t_{o f}=\frac{\sqrt{(X-x)^{2}+(Y-y)^{2}+(Z-z)^{2}}}{c} \\
& {\left[\begin{array}{ccc}
-\frac{x_{1 G}-x_{0}}{\varrho_{1 G}} & -\frac{y_{1 G}-y_{0}}{\varrho_{1 G}} & -\frac{z_{1 G}-z_{0}}{\varrho_{1 G}} \\
-\frac{x_{2 G}-x_{0}}{\varrho_{2 G}} & -\frac{y_{2 G}-y_{0}}{\varrho_{2 G}} & -\frac{z_{2 G}-z_{0}}{\varrho_{2 G}} \\
\vdots & \vdots & \vdots \\
-\frac{x_{n G}-x_{0}}{\varrho_{n G}} & -\frac{y_{n G}-y_{0}}{\varrho_{n G}} & -\frac{z_{n G}-z_{0}}{\varrho_{n G}} \\
-\frac{x_{1 R}-x_{0}}{\varrho_{1 R}} & -\frac{y_{1 R}-y_{0}}{\varrho_{1 R}} & -\frac{z_{1 R}-z_{0}}{\varrho_{1 R}} \\
\vdots & \vdots & \vdots \\
-\frac{x_{n R}-x_{0}}{\varrho_{n R}} & -\frac{y_{n R}-y_{0}}{\varrho_{n R}} & -\frac{z_{n R}-z_{0}}{\varrho_{n R}}
\end{array}\right.} \\
& 1000000 \\
& 1000000 \frac{1}{\sin e l_{1 C}} \\
& -\frac{x_{1 E}-x_{0}}{\varrho_{1 E}} \quad-\frac{y_{1 E}-y_{0}}{\varrho_{1 E}} \quad-\frac{z_{1 E}-z_{0}}{\varrho_{1 E}} \\
& 0100000 \\
& 0010000 \frac{1}{\sin e l_{1 E}} \\
& \vdots \\
& -\frac{x_{n E}-x_{0}}{Q_{n E}}-\underline{y_{n E}-y_{0}}-\underline{z_{n E}-z_{0}}
\end{aligned}
$$

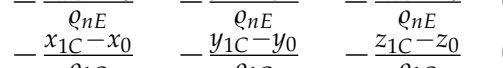

$$
\begin{aligned}
& \varrho_{1} \\
& -\frac{x_{n C}-x_{0}}{Q_{n C}} \\
& -\frac{x_{1 J}-x_{0}}{o_{1 j}} \\
& -\frac{y_{n C}-y_{0}}{\rho_{n C}}-\frac{z_{n C}-z_{0}}{\rho_{n C}} \\
& -\frac{y_{1 J}-y_{0}}{\varrho_{1 J}}-\frac{z_{1 J}-z_{0}}{\varrho_{1 J}} \\
& -\frac{x_{1 I}-x_{0}}{\varrho_{1 I}} \quad-\frac{y_{1 I}-y_{0}}{\varrho_{1 I}} \quad-\frac{z_{1 I}-z_{0}}{\varrho_{1 I}} \\
& \text { : } \quad \text { : } \\
& -\frac{x_{n I}-x_{0}}{\varrho_{n I}} \\
& -\frac{y_{n I}-y_{0}}{\varrho_{n I}} \quad-\frac{z_{n I}-z_{0}}{\varrho_{n I}} \\
& -\frac{x_{1 N}-x_{0}}{\varrho_{1 N}} \\
& \text { ! } \\
& -\frac{x_{n N}-x_{0}}{\varrho_{n N}} \\
& -\frac{y_{1 N}-y_{0}}{\varrho_{1 N}}-\frac{z_{1 N}-z_{0}}{\varrho_{1 N}} \\
& \vdots \\
& -\frac{y_{n N}-y_{0}}{\varrho_{n N}}-\frac{z_{n N}-z_{0}}{\varrho_{n N}} \\
& \left(H^{T} H\right) x=H^{T} y
\end{aligned}
$$




$$
x=\left[\begin{array}{c}
\Delta x \\
\Delta y \\
\Delta z \\
T S C_{G}+d T_{R e c} \\
T S C_{R}+d T_{R e c} \\
T S C_{E}+d T_{R e c} \\
T S C_{C}+d T_{R e c} \\
T S C_{J}+d T_{R e c} \\
T S C_{I}+d T_{R e c} \\
T S C_{N}+d T_{R e c} \\
T Z D
\end{array}\right]
$$

Table 6. Frequencies and observation codes used.

\begin{tabular}{ccccc}
\hline Constellation & \multicolumn{2}{c}{ Carrier/Frequency [MHz] } & \multicolumn{2}{c}{ Pseudorange Codes } \\
\hline GPS & L1 $(1575.42)$ & L2 $(1227.60)$ & C1C & C2W \\
GLONASS & G1 $(1602+\mathrm{k} \times 9 / 16)$ & G2 $(1246+\mathrm{k} \times 7 / 16)$ & C1C & C2P \\
Galileo & E1 $(1575.42)$ & E5b $^{1}(1207.14)$ & C1C & C7I/C7Q/C7X \\
BeiDou & B1 $(1561.098)$ & B2 $(1207.14)$ & C1I & C7I \\
QZSS & L1 $(1575.42)$ & L2 $(1227.60)$ & C1C & C2S/C2L/C2X \\
NAVIC & L5 (1176.45) & & C5A & \\
SBAS & L1 $(1575.42)$ & L5 $(1176.45)$ & C1C & C5I \\
\hline
\end{tabular}

Table 7. Explanation of symbols and variables used in Equations (2)-(6).

\begin{tabular}{|c|c|c|}
\hline Symbol & Unit & Meaning \\
\hline c & $\mathrm{m} / \mathrm{s}$ & Speed of light \\
\hline $\mathrm{t}$ & $\mathrm{s}$ & Time of reception in the receiver time scale \\
\hline $\mathrm{t}^{\prime}$ & $\mathrm{s}$ & Time of transmission in the specific GNSS time scale: $t^{\prime}=t-p(t) / c$ \\
\hline$t_{\text {of }}$ & $\mathrm{s}$ & Time of flight \\
\hline LS & $\mathrm{s}$ & $\begin{array}{l}\text { Position of satellites must be computed at time } t-t_{\text {of }}-L S \text {, where LS }=\text { full } \\
\text { leap seconds for GLONASS; } 14 \mathrm{~s} \text { for BeiDou; } 0 \mathrm{~s} \text { for other GNSS }\end{array}$ \\
\hline $\mathrm{dT}_{\text {Rel }}$ & $\mathrm{s}$ & $\begin{array}{l}\text { Periodic part of relativistic correction (which is not considered for } \\
\text { GLONASS since it is already included in the polynomial correction [3]) }\end{array}$ \\
\hline$\omega_{\mathrm{e}}$ & $\mathrm{rad} / \mathrm{s}$ & Earth rotation rate appropriate for the GNSS constellation \\
\hline$X, Y, Z$ & $\mathrm{~m}$ & Earth-Centered Earth-Fixed (ECEF) coordinates of satellite \\
\hline $\mathrm{x}, \mathrm{y}, \mathrm{z}$ & $\mathrm{m}$ & ECEF coordinates of receiver \\
\hline $\mathrm{TSC}_{\mathrm{X}}$ & $\mathrm{s}$ & Time System Correction of the $X^{1}$ GNSS relative to a common time scale \\
\hline $\mathrm{dT}_{\text {Rec }}$ & $\mathrm{s}$ & Receiver clock offset relative to a common time scale \\
\hline $\mathrm{dt}$ & $\mathrm{s}$ & Satellite Clock offset relative to a specific GNSS time scale \\
\hline TZD & $\mathrm{m}$ & Tropospheric Zenith Delay \\
\hline $\mathrm{El}$ & $\circ$ & Elevation \\
\hline
\end{tabular}

${ }^{1}$ G: GPS; R: GLONASS; E: Galileo; C: BeiDou; J: QZSS; I: NAVIC (formerly IRNSS); N: GAGAN. 
Table 8. Definition of Time Offsets.

\begin{tabular}{cc}
\hline Time Offset & Definition \\
\hline GLGP & $\left(\mathrm{TSC}_{\mathrm{R}}+\mathrm{dT}_{\mathrm{Rec}}\right)-\left(\mathrm{TSC}_{\mathrm{G}}+\mathrm{dT}_{\mathrm{Rec}}\right)$ \\
$\mathrm{GPGA}$ & $\left(\mathrm{TSC}_{\mathrm{G}}+\mathrm{dT}_{\mathrm{Rec}}\right)-\left(\mathrm{TSC}_{\mathrm{E}}+\mathrm{dT}_{\mathrm{Rec}}\right)$ \\
BDGP & $\left(\mathrm{TSC}_{\mathrm{C}}+\mathrm{dT}_{\mathrm{Rec}}\right)-\left(\mathrm{TSC}_{\mathrm{G}}+\mathrm{dT}_{\mathrm{Rec}}\right)$ \\
QZGP & $\left(\mathrm{TSC}_{\mathrm{J}}+\mathrm{dT}_{\mathrm{Rec}}\right)-\left(\mathrm{TSC}_{\mathrm{G}}+\mathrm{dT}_{\mathrm{Rec}}\right)$ \\
NAGP & $\left(\mathrm{TSC}_{\mathrm{I}}+\mathrm{dT}_{\mathrm{Rec}}\right)-\left(\mathrm{TSC}_{\mathrm{G}}+\mathrm{dT}_{\mathrm{Rec}}\right)$ \\
GNGP & $\left(\mathrm{TSC}_{\mathrm{N}}+\mathrm{dT}_{\mathrm{Rec}}\right)-\left(\mathrm{TSC}_{\mathrm{G}}+\mathrm{dT}_{\mathrm{Rec}}\right)$ \\
\hline
\end{tabular}

\section{Results of the Positioning Analyses}

Daily analysis has been performed on the 31 stations listed in Table 1 and shown in Figure 1 starting from 1 January 2014 and is currently ongoing. Figure 8 shows the time series of GLGP, GPGA, BDGP and QZGP, distinguishing between the five types of receiver.

In the GLGP time series a very large misalignment of about $-400 \mathrm{~ns}$ from the beginning of the analyses until mid-August 2014 can be seen. Then a re-aligning procedure started and was completed at the end of 2014. From the beginning of 2015 the GLONASS time scale is generally kept aligned with GPS, but several short-term variations with amplitudes ranging from tens to about one hundred ns are evident. The largest variation observed happened from July to December of 2016, and has a sinusoidal shape with an amplitude of about $100 \mathrm{~ns}$.

BDGP varies continuously, with an oscillating trend and amplitude of about $70 \mathrm{~ns}$. Furthermore the oscillations have a positive mean, which results in an average positive offset of the BeiDou time scale with respect to GPS. Considering a time series of more than three years it is possible to notice a slow trend toward zero, but it is not clear if this long-term variation is effectively a re-alignment procedure of the BeiDou time scale to GPS.

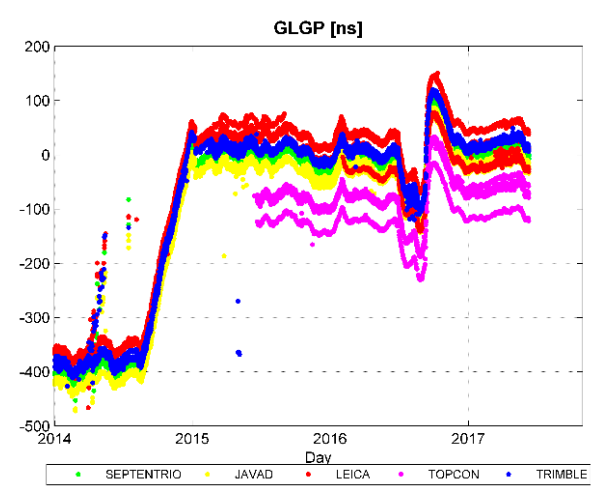

(a)

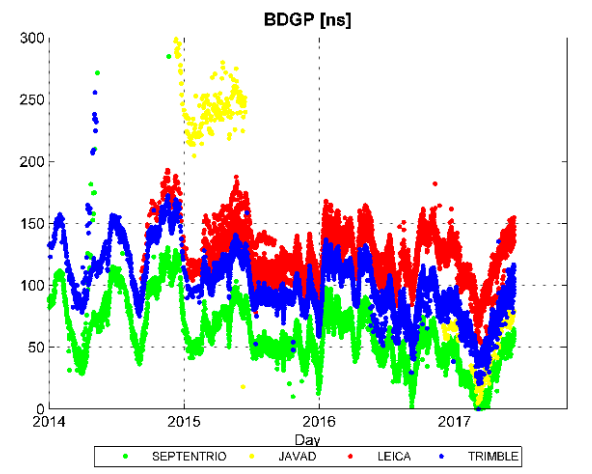

(c)

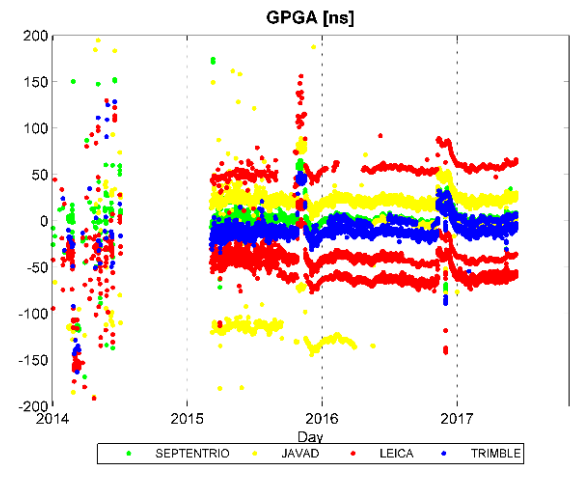

(b)

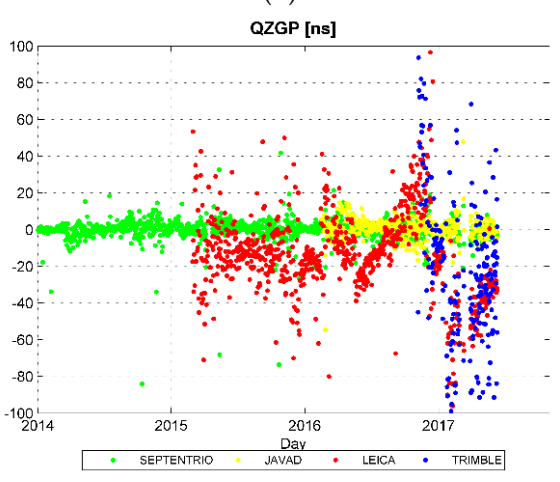

(d)

Figure 8. Time series since 1 January 2014 of offsets of the GLONASS (a), Galileo (b), BeiDou (c) and QZSS (d) time scales relative to GPS. 
GPGA is aligned with GPS, since the time offset series are almost constant in time and centered to zero. Two sudden variations took place in November 2015 and November-December 2016, measuring about 60 and $30 \mathrm{~ns}$, respectively.

The QZGP system time is aligned with GPS, but unfortunately for this system data from only five of the 31 stations is available. Among these five stations, Leica and Trimble receivers show higher scattered results compared to those of Septentrio and Javad, despite the global average value is very close to zero. It is important to notice that until June of 2017 there was only one satellite belonging to QZSS, so QZGP actually represents the time offset between this single satellite and GPS.

\subsection{Differential Time Offset}

A receiver-dependent bias is clearly visible in Figure 8, as previously noted by $[17,20,21]$. In order to better investigate this receiver dependent bias, the time series relative to the mean values of Septentrio stations have been differentiated. The choice of Septentrio is due to the observation that these stations show very similar values: for each day the RMS is generally lower than $3 \mathrm{~ns}$. Figure 9 shows the time series of GLGP, GPGA and BDGP obtained for individual Septentrio stations. The QZGP time series is not shown since there is only one station among the six Septentrio stations which tracks this constellation.

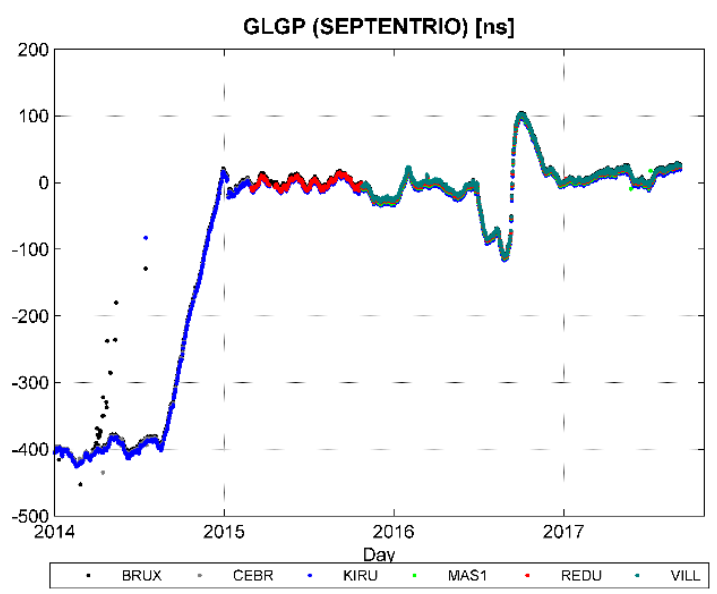

(a)

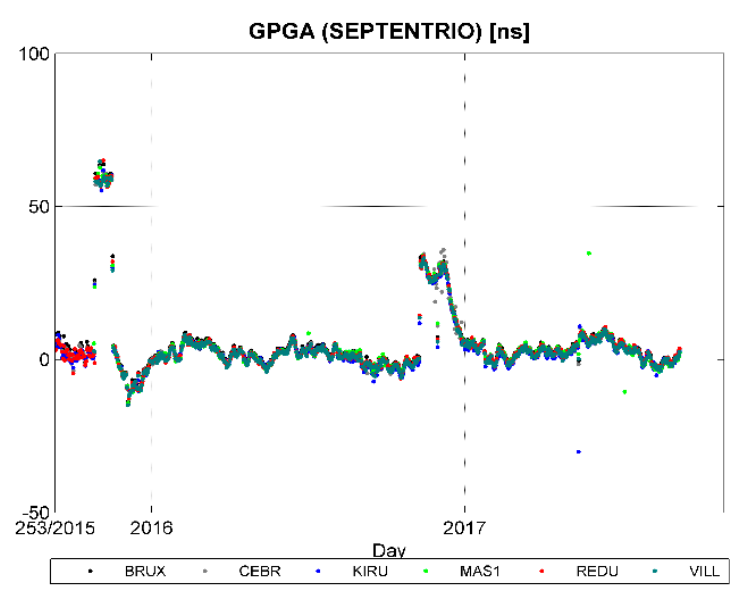

(b)

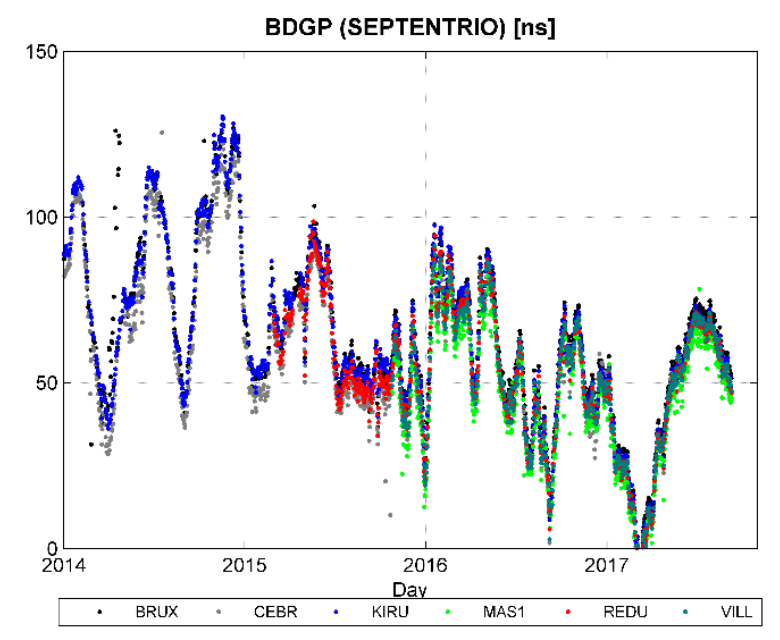

(c)

Figure 9. Time series since 1 January 2014 of offsets of the GLONASS (a), Galileo (b) and BeiDou (c) time scales of Septentrio stations relative to GPS. 
The graph of GPGA in Figure 10 starts from 9 October 2015 due to the high scatter observed before this date. From these graphs the receiver dependent bias can be monitored. It is worth noting that for a given receiver type, some stations show similar time offsets, so their time series are quite superimposed, whereas other stations show different values and this difference seems to be constant in time. For example in Figure 10a it is possible to notice that the Trimble and Javad receivers have very similar time offsets, whereas Leica and Topcon show a relative bias up to tens of nanoseconds.

In Figure 10a a discontinuity of several Leica stations from about $40 \mathrm{~ns}$ to about $-25 \mathrm{~ns}$ in the first half of 2016 is evident. These stations are: CAEN, MOSE, MLVL, PADO, REYK (Table 1). Taking into account the station logsheets it was possible to identify an exact connection between some of the discontinuities in the time offset series and receivers' firmware updates. For example, considering the five Leica stations mentioned above, the correspondence between the discontinuity in the GLGP time offset and the update of receivers firmware for MOSE, PADO and REYK could be observed.

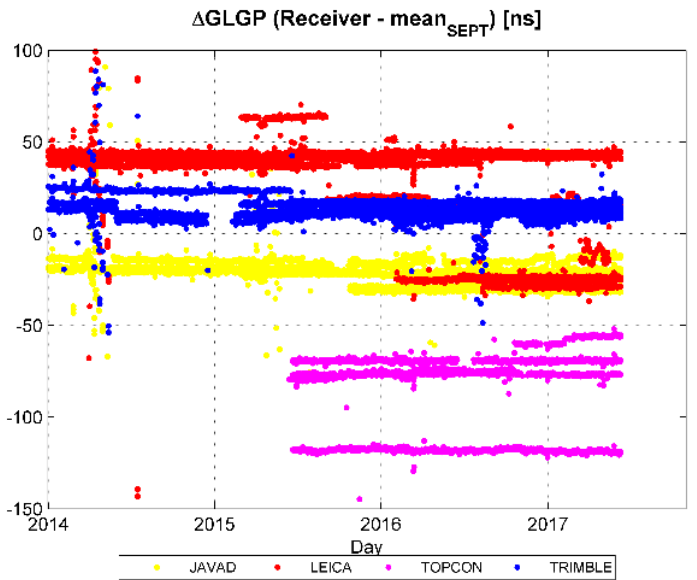

(a)

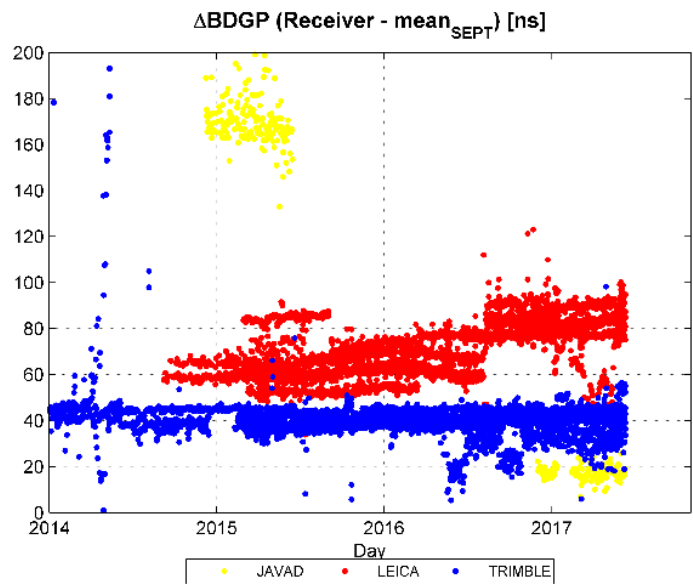

(c)

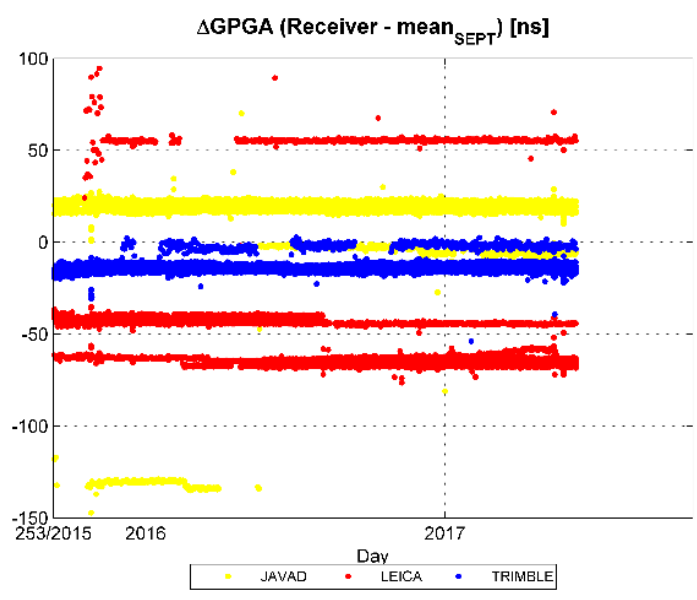

(b)

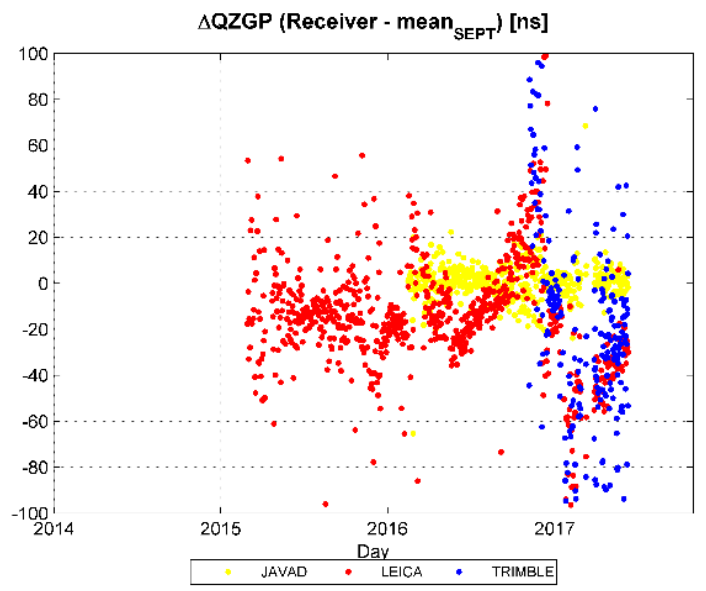

(d)

Figure 10. Time series since 1 January 2014 of offsets of GLGP (a), GPGA (b), BDGP (c) and QZGP (d) differentiated relative to Septentrio.

\subsection{Analysis of Other Constellations: NAVIC and GAGAN}

The multiGNSS software [4] has the capability to analyze the observations from NAVIC and SBAS, in addition to GPS, GLONASS, Galileo, BeiDou and QZSS. Septentrio has kindly made available RINEX data of days 25-29 May 2017 from their station located in Brussels (not listed in Table 1). This gave the opportunity to analyze the NAVIC time offsets for these five days. This station is equipped with a POLARX5 5.11 receiver, referred to as SEPT hereafter. It is worth noting that the observation 
data of the NAVIC satellites are available for the L5 carrier only, for which NAVIC has been processed in single frequency.

Figure 11a shows the results. The offset of NAVIC time scale relative to GPS is colored in purple. The NAVIC time offset is characterized by a daily variation which can reach $20 \mathrm{~ns}$. Across the five days, NAGP seems to be quite constant, with a mean value of about $-85 \pm 9$ ns.

Figure $11 \mathrm{~b}$ shows the time offsets of SEPT differentiated to the other six Septentrio stations currently analyzed. GLGP and BDGP are smaller than those of other stations, whereas GPGA is very close. More in detail, the difference of GLGP varies suddenly from -16.5 to -7.5 ns on 26 May 2017, with a standard deviation of $3 \mathrm{~ns}$. The GPGA of six Septentrio stations show spikes at 12:00 and 24:00 of each day, whereas SEPT does not. Otherwise the alignment is within $1 \mathrm{~ns}$. The difference of BDGP is almost constant, with a mean value of about $-12.5 \pm 5 \mathrm{~ns}$.

For SBAS data for satellites S27 and S28, both belonging to the Indian overlay system GAGAN in geostationary orbits have been used. These satellites are tracked by seven stations (DLF1, KIRU, REDU, TLSE, WTZ3, WTZZ, ZIMJ). The GAGAN data were analyzed only from 25 September 2016, so as yet not enough results are available to perform a calibration of the GAGAN time offset like those described in the previous paragraph.

Figure 12 shows the results obtained. Trimble stations give higher offsets, Javad stations give lower offsets and Septentrio stations give offsets comprised of those from the previous two receiver types. Septentrio GNGP seems to be quite constant in time, whereas for Trimble and Javad higher variations are observed.

SEPTENTRIO Time Offset [ns] - 145-149/2017

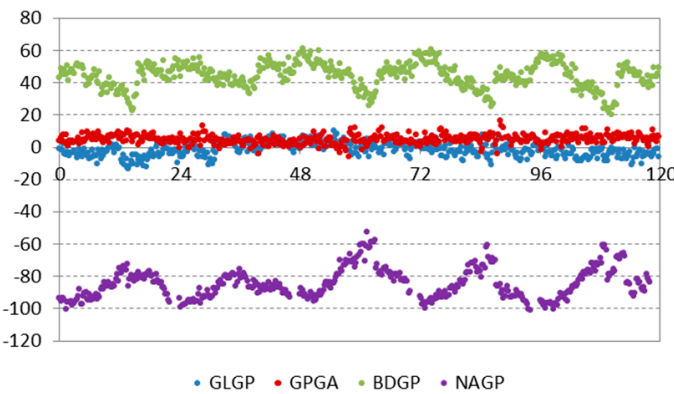

(a)

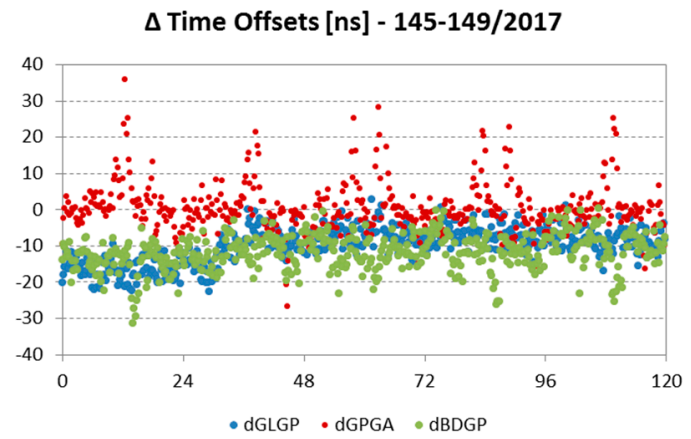

(b)

Figure 11. Time offsets of Septentrio station. (a) Time offsets of GLONASS, Galileo, BeiDou and NAVIC (purple) relative to GPS; (b) GLGP, GPGA and BDGP relative to the other Septentrio stations.

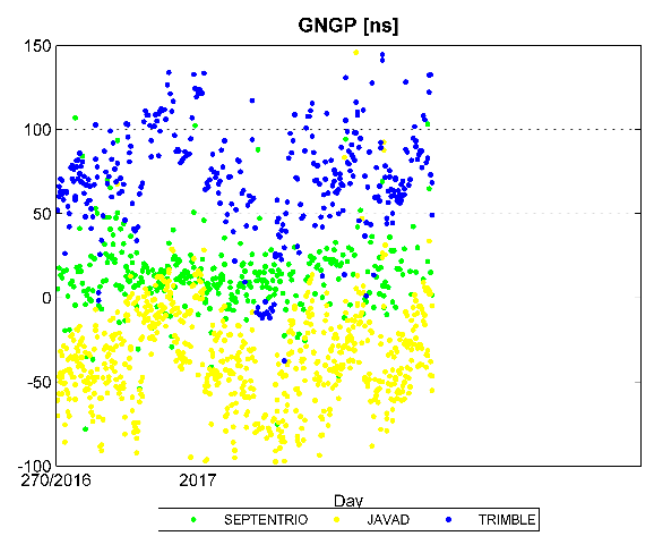

Figure 12. Time series since 25 September 2016 of offset of the GAGAN time scale relative to GPS. 


\section{Discussion}

The observed correspondences between the discontinuities in the time offset series and receiver firmware updates suggest a relationship between the two events. In order to better investigate this relationship, the information about receiver set up and the time offsets relative to Septentrio have been summarized in Table 9. In this table the marker name of a station is followed by a lowercase letter if at least one discontinuity in time offset series is observed. The lowercase letter indicates a continuity period of time offsets, so a station name associated with the same letter has the same time offsets.

For each station every row corresponds to a new receiver set up or new time offsets relative to Septentrio, or both the events: in this case the discontinuity of time offsets corresponds to an update of receiver set up. These correspondences are highlighted by using a bold font.

A total number of 19 discontinuities have been identified. Among these, 11 are connected to receiver updates and six are due to unknown causes. Two of the 11 discontinuities connected to a receiver update involve also the antenna: COMOc and GANPc, as it can be noticed in Table 1 . The other two discontinuities are linked to changes in antenna configuration: TLSEb shows a discontinuity on 11 March 2016, when the alignment from Nord was changed from 0 to -140 degrees, WTZZb shows a discontinuity on 13 July 2015, when the ARP (Antenna Reference Point) Up was changed from 0.045 to $0.284 \mathrm{~m}$.

In Table 9 there are 92 receiver firmware updates, only 11 of these are connected with a discontinuity in time offset. So most of the receiver updates do not imply a discontinuity in time offset. Conversely more than half of the discontinuities in time offsets are connected to an update of receiver firmware. For these reasons it is necessary to keep monitoring both the configuration changes of receivers and the time series of time offsets. 
Table 9. Calibration of station's time offsets relative to Septentrio.

\begin{tabular}{|c|c|c|c|c|c|c|c|c|c|}
\hline \multicolumn{3}{|c|}{ STATION } & \multicolumn{3}{|c|}{ RECEIVER } & \multicolumn{4}{|c|}{ CALIBRATION [ns] } \\
\hline ID & FROM & TO & RECEIVER & TYPE & FIRMWARE & dGLGP & dGPGA & dBDGP & dQZGP \\
\hline BBYSa & 1 January 2014 & 30 May 2014 & TRIMBLE & NETR9 & $4.81 / 4.71$ & $16.5 \pm 2.7$ & & $44.4 \pm 2.8$ & \\
\hline BBYSb & 30 May 2014 & NOW $^{1}$ & TRIMBLE & NETR9 & $4.85 / 4.71$ & $10.6 \pm 0.9$ & $-12.4 \pm 0.8$ & $40.1 \pm 1.7$ & \\
\hline BOGO & 21 June 2015 & $\mathrm{NOW}^{1}$ & TOPCON & EUROCARD & 2.6.1 10 January 2008 & $-118.1 \pm 1.1$ & & & \\
\hline BRST & 1 January 2014 & 26 March 2014 & TRIMBLE & NETR9 & 4.81 & $11.1 \pm 1.2$ & $-12.0 \pm 1.1$ & $38.9 \pm 2.4$ & \\
\hline BRST & 26 March 2014 & NOW $^{1}$ & $\begin{array}{l}\text { TRIMBLE } \\
\text { TRLE }\end{array}$ & NETR9 & $\begin{array}{l}4.01 \\
4.85\end{array}$ & $11.1 \pm 1.2$ & $-12.0 \pm 1.1$ & $38.9 \pm 2.4$ & \\
\hline BRUX & 1 January 2014 & 17 March 2014 & SEPTENTRIO & POLARX4TR & 2.3 .4 & $2.8 \pm 2.7$ & $0.6 \pm 0.6$ & $3.4 \pm 3.3$ & \\
\hline BRUX & 17 March 2014 & 7 September 2015 & SEPTENTRIO & POLARX4TR & 2.5 .2 & $2.8 \pm 2.7$ & $0.6 \pm 0.6$ & $3.4 \pm 3.3$ & \\
\hline BRUX & 7 September 2015 & 24 October 2016 & SEPTENTRIO & POLARX4TR & 2.9 .0 & $2.8 \pm 2.7$ & $0.6 \pm 0.6$ & $3.4 \pm 3.3$ & \\
\hline BRUX & 24 October 2016 & 3 January 2017 & SEPTENTRIO & POLARX4TR & 2.9 .5 & $2.8 \pm 2.7$ & $0.6 \pm 0.6$ & $3.4 \pm 3.3$ & \\
\hline BRUX & 3 January 2017 & NOW $^{1}$ & SEPTENTRIO & POLARX4TR & 2.9 .6 & $2.8 \pm 2.7$ & $0.6 \pm 0.6$ & $3.4 \pm 3.3$ & \\
\hline CAENa & 1 January 2014 & 20 February 2014 & LEICA & GR25 & 3.01 & $41.5 \pm 3.2$ & $-42.1 \pm 1.1$ & $68.0 \pm 3.3$ & \\
\hline CAENa & 19 September 2014 & 6 November 2014 & LEICA & GR25 & 3.10 & $41.5 \pm 3.2$ & $-42.1 \pm 1.1$ & $68.0 \pm 3.3$ & \\
\hline CAENa & 6 November 2014 & 5 August 2016 & LEICA & GR25 & 3.11 & $41.5 \pm 3.2$ & $-42.1 \pm 1.1$ & $68.0 \pm 3.3$ & \\
\hline CAENb & 12 August 2016 & 9 November 2016 & LEICA & GR25 & 3.11 & $-23.9 \pm 0.5$ & $-65.3 \pm 1.0$ & $90.3 \pm 2.7$ & \\
\hline CAENb & 9 November 2016 & NOW $^{1}$ & LEICA & GR25 & 4.02 & $-23.9 \pm 0.5$ & $-65.3 \pm 1.0$ & $90.3 \pm 2.7$ & \\
\hline CEBR & 1 January 2014 & 10 December 2014 & SEPTENTRIO & POLARX4 & 2.5.1p1 & $-0.3 \pm 2.8$ & $0.0 \pm 0.9$ & $-2.9 \pm 3.2$ & \\
\hline CEBR & 10 December 2014 & 27 August 2015 & SEPTENTRIO & POLARX4 & 2.5.2-esa3 & $-0.3 \pm 2.8$ & $0.0 \pm 0.9$ & $-2.9 \pm 3.2$ & \\
\hline CEBR & 27 August 2015 & 21 October 2016 & SEPTENTRIO & POLARX4 & 2.9 .0 & $-0.3 \pm 2.8$ & $0.0 \pm 0.9$ & $-2.9 \pm 3.2$ & \\
\hline CEBR & 21 October 2016 & NOW $^{1}$ & SEPTENTRIO & POLARX4 & 2.9.5-extref1 & $-0.3 \pm 2.8$ & $0.0 \pm 0.9$ & $-2.9 \pm 3.2$ & \\
\hline COMOa & 21 June 2015 & 19 October 2016 & TOPCON & E_GGD & 3.412 Decembaer 2009 p2 & $-76.2 \pm 2.0$ & & & \\
\hline $\mathrm{COMOb}$ & 19 October 2016 & 7 February 2017 & TOPCON & NET-G5 & 5.020 November 2015 p2 & $-60.2 \pm 0.7$ & & & \\
\hline COMOc & 7 February 2017 & NOW $^{1}$ & TOPCON & NET-G5 & 5.17 September 2016 & $-56.0 \pm 0.8$ & & & \\
\hline DLF1a & 1 January 2014 & 17 June 2015 & TRIMBLE & NETR9 & 4.81 & $23.6 \pm 1.8$ & & $44.8 \pm 1.4$ & \\
\hline DLF1b & 20 July 2016 & 21 December 2016 & TRIMBLE & NETR9 & 5.14 & $17.4 \pm 0.9$ & $-16.2 \pm 1.0$ & $42.2 \pm 1.4$ & $-102.9 \pm 149.4$ \\
\hline DLF1b & 21 December 2016 & 28 May 2017 & TRIMBLE & NETR9 & 5.15 & $17.4 \pm 0.9$ & $-16.2 \pm 1.0$ & $42.2 \pm 1.4$ & $-102.9 \pm 149.4$ \\
\hline DLF1b & 28 May 2017 & NOW $^{1}$ & TRIMBLE & NETR9 & 5.22 & $17.4 \pm 0.9$ & $-16.2 \pm 1.0$ & $42.2 \pm 1.4$ & $-102.9 \pm 149.4$ \\
\hline DYNGa & 2 March 2015 & 19 June 2015 & TRIMBLE & NETR9 & 4.85 & $12.3 \pm 1.4$ & $-13.0 \pm 1.3$ & $38.0 \pm 2.1$ & \\
\hline DYNGa & 19 June 2015 & 5 July 2016 & TRIMBLE & NETR9 & 5.01 & $12.3 \pm 1.4$ & $-13.0 \pm 1.3$ & $38.0 \pm 2.1$ & \\
\hline DYNGb & 05 July 2016 & 14 December 2016 & TRIMBLE & NETR9 & 5.14 & $15.4 \pm 1.7$ & $-13.6 \pm 1.1$ & $44.1 \pm 1.4$ & \\
\hline DYNGb & 14 December 2016 & NOW $^{1}$ & TRIMBLE & NETR9 & 5.15 & $15.4 \pm 1.7$ & $-13.6 \pm 1.1$ & $44.1 \pm 1.4$ & \\
\hline GANPa & 1 January 2014 & 30 May 2014 & TRIMBLE & NETR9 & $4.81 / 4.29$ & $13.0 \pm 2.6$ & & $40.5 \pm 1.5$ & \\
\hline GANPb & 30 May 2014 & 10 February 2015 & TRIMBLE & NETR9 & $4.85 / 4.29$ & $10.3 \pm 3.6$ & $-14.7 \pm 2.1$ & $38.5 \pm 3.4$ & $-21.8 \pm 53.1$ \\
\hline GANPb & 10 February 2015 & 18 November 2015 & TRIMBLE & NETR9 & $4.93 / 4.93$ & $10.3 \pm 3.6$ & $-14.7 \pm 2.1$ & $38.5 \pm 3.4$ & $-21.8 \pm 53.1$ \\
\hline GANPb & 18 November 2015 & 14 October 2016 & TRIMBLE & NETR9 & $5.10 / 5.02$ & $10.3 \pm 3.6$ & $-14.7 \pm 2.1$ & $38.5 \pm 3.4$ & $-21.8 \pm 53.1$ \\
\hline GANPb & 14 October 2016 & 2 January 2017 & TRIMBLE & NETR9 & $5.14 / 5.14$ & $10.3 \pm 3.6$ & $-14.7 \pm 2.1$ & $38.5 \pm 3.4$ & $-21.8 \pm 53.1$ \\
\hline GANPb & 2 January 2017 & 11 January 2017 & TRIMBLE & NETR9 & $5.15 / 5.15$ & $10.3 \pm 3.6$ & $-14.7 \pm 2.1$ & $38.5 \pm 3.4$ & $-21.8 \pm 53.1$ \\
\hline GANPb & 11 January 2017 & 6 February 2017 & TRIMBLE & NETR9 & $5.20 / 5.20$ & $10.3 \pm 3.6$ & $-14.7 \pm 2.1$ & $38.5 \pm 3.4$ & $-21.8 \pm 53.1$ \\
\hline GANPc & 6 February 2017 & 18 April 2017 & TRIMBLE & NETR9 & 5.20 & $17.4 \pm 0.9$ & $-11.0 \pm 0.9$ & $44.9 \pm 0.8$ & $-30.4 \pm 30.6$ \\
\hline GANPc & 18 April 2017 & NOW $^{1}$ & TRIMBLE & NETR9 & 5.22 & $17.4 \pm 0.9$ & $-11.0 \pm 0.9$ & $44.9 \pm 0.8$ & $-30.4 \pm 30.6$ \\
\hline GOP7a & 1 January 2014 & 21 August 2015 & JAVAD & TRE_G3TH DELTA & 3.5.1 & $-19.0 \pm 1.3$ & & & \\
\hline
\end{tabular}


Table 9. Cont.

\begin{tabular}{|c|c|c|c|c|c|c|c|c|c|}
\hline \multicolumn{3}{|c|}{ STATION } & \multicolumn{3}{|c|}{ RECEIVER } & \multicolumn{4}{|c|}{ CALIBRATION [ns] } \\
\hline ID & FROM & TO & RECEIVER & TYPE & FIRMWARE & dGLGP & dGPGA & dBDGP & dQZGP \\
\hline GOP7b & 21 August 2015 & NOW $^{1}$ & TRIMBLE & NETR9 & 5.01 & $10.6 \pm 3.0$ & $-4.9 \pm 4.6$ & $35.1 \pm 3.1$ & \\
\hline HOFN & 1 January 2014 & 18 February 2014 & LEICA & GR25 & $3.01 / 6.212$ & $43.8 \pm 3.5$ & $-44.2 \pm 0.8$ & & \\
\hline HOFN & 18 February 2014 & 8 September 2014 & LEICA & GR25 & $3.03 / 6.214$ & $43.8 \pm 3.5$ & $-44.2 \pm 0.8$ & & \\
\hline HOFN & 8 September 2014 & 10 September 2014 & LEICA & GR25 & $3.10 / 6.403$ & $43.8 \pm 3.5$ & $-44.2 \pm 0.8$ & & \\
\hline HOFN & 10 September 2014 & 3 November 2014 & LEICA & GR25 & $3.10 .1633 / 6.403$ & $43.8 \pm 3.5$ & $-44.2 \pm 0.8$ & & \\
\hline HOFN & 3 November 2014 & NOW $^{1}$ & LEICA & GR25 & 3.11.1639/6.403 & $43.8 \pm 3.5$ & $-44.2 \pm 0.8$ & & \\
\hline IGMI & 21 June 2015 & 17 June 2016 & TOPCON & ODYSSEY_E & 3.310 July 2008 P4 & $-69.3 \pm 1.5$ & & & \\
\hline IGMI & 21 July 2016 & NOW $^{1}$ & TOPCON & ODYSSEY_E & 3.412 December 2009 P2 & $-69.3 \pm 1.5$ & & & \\
\hline KIRU & 1 January 2014 & 10 December 2014 & SEPTENTRIO & POLARX4 & $2.5 .1 \mathrm{p} 1$ & $-3.4 \pm 2.1$ & $-0.4 \pm 1.2$ & $2.1 \pm 3.8$ & $0.0 \pm 0.0$ \\
\hline KIRU & 10 December 2014 & 27 August 2015 & SEPTENTRIO & POLARX4 & 2.5.2-esa3 & $-3.4 \pm 2.1$ & $-0.4 \pm 1.2$ & $2.1 \pm 3.8$ & $0.0 \pm 0.0$ \\
\hline KIRU & 27 August 2015 & 21 October 2016 & SEPTENTRIO & POLARX4 & 2.9 .0 & $-3.4 \pm 2.1$ & $-0.4 \pm 1.2$ & $2.1 \pm 3.8$ & $0.0 \pm 0.0$ \\
\hline KIRU & 21 October 2016 & NOW $^{1}$ & SEPTENTRIO & POLARX4 & 2.9.5-extref1 & $-3.4 \pm 2.1$ & $-0.4 \pm 1.2$ & $2.1 \pm 3.8$ & $0.0 \pm 0.0$ \\
\hline MOSEa & 1 January 2014 & 24 February 2014 & LEICA & GR25 & $3.00 / 6.113$ & $41.1 \pm 4.1$ & & & \\
\hline MOSEa & 24 February 2014 & 17 July 2014 & LEICA & GR25 & $3.03 / 6.214$ & $41.1 \pm 4.1$ & & & \\
\hline MOSEa & 17 July 2014 & 11 September 2014 & LEICA & GR25 & $3.10 / 6.401$ & $41.1 \pm 4.1$ & & & \\
\hline MOSEa & 11 September 2014 & 26 November 2014 & LEICA & GR25 & $3.10 / 6.403$ & $41.1 \pm 4.1$ & & & \\
\hline MOSEa & 26 November 2014 & 8 May 2015 & LEICA & GR25 & $3.11 / 6.403$ & $41.1 \pm 4.1$ & & & \\
\hline MOSEa & 8 May 2015 & 2 February 2016 & LEICA & GR25 & $3.20 / 6.403$ & $41.1 \pm 4.1$ & & & \\
\hline MOSEb & 2 February 2016 & 03 April 2017 & LEICA & GR25 & $3.22 / 6.521$ & $-24.9 \pm 0.6$ & $-67.4 \pm 0.8$ & & \\
\hline MOSEb & 3 April 2017 & NOW $^{1}$ & LEICA & GR25 & $4.11 / 6.523$ & $-24.9 \pm 0.6$ & $-67.4 \pm 0.8$ & & \\
\hline MAS1 & 25 October 2015 & 18 October 2016 & SEPTENTRIO & POLARX4 & 2.9 .0 & $-1.2 \pm 0.8$ & $0.2 \pm 1.2$ & $-4.3 \pm 2.3$ & \\
\hline MAS1 & 18 October 2016 & NOW $^{1}$ & SEPTENTRIO & POLARX4 & 2.9.5-extref1 & $-1.2 \pm 0.8$ & $0.2 \pm 1.2$ & $-4.3 \pm 2.3$ & \\
\hline MLVLa & 1 January 2014 & 29 January 2014 & LEICA & GR25 & 3.01 & $37.3 \pm 2.8$ & $-39.8 \pm 1.2$ & $59.4 \pm 2.3$ & \\
\hline MLVLa & 29 January 2014 & 29 August 2014 & LEICA & GR25 & 3.03 & $37.3 \pm 2.8$ & $-39.8 \pm 1.2$ & $59.4 \pm 2.3$ & \\
\hline MLVLa & 29 August 2014 & 20 October 2014 & LEICA & GR25 & 3.10 & $37.3 \pm 2.8$ & $-39.8 \pm 1.2$ & $59.4 \pm 2.3$ & \\
\hline MLVLa & 20 October 2014 & 6 August 2016 & LEICA & GR25 & 3.11 & $37.3 \pm 2.8$ & $-39.8 \pm 1.2$ & $59.4 \pm 2.3$ & \\
\hline MLVLb & 11 August 2016 & 9 November 2016 & LEICA & GR25 & 3.11 & $-28.9 \pm 0.7$ & $-63.0 \pm 1.0$ & $81.9 \pm 2.7$ & \\
\hline MLVLb & 9 November 2016 & NOW $^{1}$ & LEICA & GR25 & 4.02 & $-28.9 \pm 0.7$ & $-63.0 \pm 1.0$ & $81.9 \pm 2.7$ & \\
\hline NYA2 & 25 October 2015 & 25 October 2016 & JAVAD & TRE_G3TH DELTA & 3.5 .10 & $-29.3 \pm 0.8$ & $18.2 \pm 1.6$ & & $0.6 \pm 8.0$ \\
\hline NYA2 & 25 October 2016 & NOW $^{1}$ & JAVAD & TRE_G3TH DELTA & 3.6.7 & $-29.3 \pm 0.8$ & $18.2 \pm 1.6$ & & $0.6 \pm 8.0$ \\
\hline OBE4 & 25 October 2015 & 17 October 2016 & JAVAD & TRE_G3TH DELTA & 3.5 .10 & $-31.1 \pm 0.7$ & $22.3 \pm 1.0$ & & \\
\hline OBE4 & 17 October 2016 & NOW $^{1}$ & JAVAD & TRE_G3TH DELTA & 3.6 .7 & $-31.1 \pm 0.7$ & $22.3 \pm 1.0$ & & \\
\hline PADOa & 1 January 2014 & 25 August 2014 & LEICA & GR10 & $3.00 / 6.113$ & $40.7 \pm 4.4$ & $-41.4 \pm 1.3$ & $53.2 \pm 2.2$ & \\
\hline PADOa & 25 August 2014 & 15 March 2016 & LEICA & GR10 & $3.10 .1633 / 6.403$ & $40.7 \pm 4.4$ & $-41.4 \pm 1.3$ & $53.2 \pm 2.2$ & \\
\hline PADOb & 15 March 2016 & 15 June 2016 & LEICA & GR10 & $3.22 / 6.521$ & $-25.3 \pm 1.4$ & $-64.7 \pm 0.3$ & $77.6 \pm 1.8$ & \\
\hline PADOb & 15 June 2016 & 24 August 2016 & LEICA & GR10 & $4.00 / 6.521$ & $-25.3 \pm 1.4$ & $-64.7 \pm 0.3$ & $77.6 \pm 1.8$ & \\
\hline PADOb & 24 August 2016 & NOW $^{1}$ & LEICA & GR10 & $4.00 / 6.522$ & $-25.3 \pm 1.4$ & $-64.7 \pm 0.3$ & $77.6 \pm 1.8$ & \\
\hline PEN2 & 2 March 2015 & NOW $^{1}$ & LEICA & GRX1200 + GNSS & $8.51 / 6.110$ & $41.6 \pm 2.7$ & $54.9 \pm 3.5$ & & \\
\hline POTS & 2 March 2015 & 15 September 2015 & JAVAD & TRE_G3TH DELTA & 3.4.7 & $-21.8 \pm 0.8$ & $16.8 \pm 1.1$ & & \\
\hline POTS & 15 September 2015 & 25 October 2016 & JAVAD & TRE_G3TH DELTA & 3.5 .10 & $-21.8 \pm 0.8$ & $16.8 \pm 1.1$ & & \\
\hline POTS & 25 October 2016 & NOW $^{1}$ & JAVAD & TRE_G3TH DELTA & 3.6 .7 & $-21.8 \pm 0.8$ & $16.8 \pm 1.1$ & & \\
\hline REDU & 2 March 2015 & 27 August 2015 & SEPTENTRIO & POLARX4 & 2.5.2-esa3 & $0.3 \pm 0.4$ & $0.0 \pm 0.9$ & $-0.4 \pm 1.2$ & \\
\hline REDU & 27 August 2015 & 18 October 2016 & SEPTENTRIO & POLARX4 & 2.9 .0 & $0.3 \pm 0.4$ & $0.0 \pm 0.9$ & $-0.4 \pm 1.2$ & \\
\hline REDU & 18 October 2016 & NOW $^{1}$ & SEPTENTRIO & POLARX4 & 2.9.5-extref1 & $0.3 \pm 0.4$ & $0.0 \pm 0.9$ & $-0.4 \pm 1.2$ & \\
\hline REYKa & 2 March 2015 & 8 August 2016 & LEICA & GR25 & $3.11 .1639 / 6.403$ & $42.8 \pm 1.2$ & $-43.9 \pm 0.8$ & $62.0 \pm 2.4$ & \\
\hline REYKb & 8 August 2016 & NOW $^{1}$ & LEICA & GR25 & $3.11 .1639 / 6.522$ & $-24.4 \pm 0.7$ & $-67.0 \pm 0.9$ & $83.8 \pm 3.0$ & \\
\hline SULP & 21 June 2015 & 11 November 2016 & TOPCON & NET-G3A & 4.1 31 May 2013 & $-76.5 \pm 1.3$ & & & \\
\hline SULP & 16 November 2016 & NOW $^{1}$ & TOPCON & NET-G3A & 4.723 October 2015 & $-76.5 \pm 1.3$ & & & \\
\hline TLSEa & 2 March 2015 & 19 June 2015 & TRIMBLE & NETR9 & 4.85 & $15.9 \pm 0.9$ & $-13.6 \pm 1.6$ & $43.1 \pm 2.1$ & \\
\hline TLSEa & 19 June 2015 & 11 March 2016 & TRIMBLE & NETR9 & 5.01 & $15.9 \pm 0.9$ & $-13.6 \pm 1.6$ & $43.1 \pm 2.1$ & \\
\hline TLSEb & 11 March 2016 & 11 August 2016 & TRIMBLE & NETR9 & 5.01 & $13.6 \pm 0.9$ & $-14.7 \pm 0.6$ & $44.8 \pm 0.9$ & \\
\hline
\end{tabular}


Table 9. Cont

\begin{tabular}{|c|c|c|c|c|c|c|c|c|c|}
\hline \multicolumn{3}{|c|}{ STATION } & \multicolumn{3}{|c|}{ RECEIVER } & \multicolumn{4}{|c|}{ CALIBRATION [ns] } \\
\hline ID & FROM & TO & RECEIVER & TYPE & FIRMWARE & dGLGP & dGPGA & dBDGP & dQZGP \\
\hline TLSEb & 11 August 2016 & 12 December 2016 & TRIMBLE & NETR9 & 5.14 & $13.6 \pm 0.9$ & $-14.7 \pm 0.6$ & $44.8 \pm 0.9$ & \\
\hline TLSEb & 12 December 2016 & 23 May 2017 & TRIMBLE & NETR9 & 5.15 & $13.6 \pm 0.9$ & $-14.7 \pm 0.6$ & $44.8 \pm 0.9$ & \\
\hline TLSEb & 23 May 2017 & 15 June 2017 & TRIMBLE & NETR9 & 5.22 & $13.6 \pm 0.9$ & $-14.7 \pm 0.6$ & $44.8 \pm 0.9$ & \\
\hline TLSEb & 15 June 2017 & NOW $^{1}$ & TRIMBLE & NETR9 & 5.22 & $13.6 \pm 0.9$ & $-14.7 \pm 0.6$ & $44.8 \pm 0.9$ & \\
\hline VILL & 25 October 2015 & 21 October 2016 & SEPTENTRIO & POLARX4 & 2.9 .0 & $2.1 \pm 0.5$ & $-0.3 \pm 0.8$ & $-0.7 \pm 1.1$ & \\
\hline VILL & 21 October 2016 & NOW $^{1}$ & SEPTENTRIO & POLARX4 & 2.9.5-extref1 & $2.1 \pm 0.5$ & $-0.3 \pm 0.8$ & $-0.7 \pm 1.1$ & \\
\hline WROCa & 2 March 2015 & 4 September 2015 & LEICA & GR25 & 3.11.1639/6.403 & $63.2 \pm 1.4$ & & $84.7 \pm 1.8$ & $-12.7 \pm 18.3$ \\
\hline WROCb & 4 September 2015 & 10 March 2016 & LEICA & GR25 & $3.21 / 6.403$ & $19.8 \pm 1.3$ & $-62.8 \pm 0.9$ & $72.8 \pm 2.1$ & $-13.5 \pm 20.1$ \\
\hline WROCb & 10 March 2016 & 14 April 2016 & LEICA & GR25 & $3.22 / 6.521$ & $19.8 \pm 1.3$ & $-62.8 \pm 0.9$ & $72.8 \pm 2.1$ & $-13.5 \pm 20.1$ \\
\hline WROCc & 15 April 2016 & 23 May 2016 & LEICA & GR25 & $3.22 / 6.521$ & $12.1 \pm 10.1$ & $-62.4 \pm 2.0$ & $72.0 \pm 9.2$ & $-14.3 \pm 27.2$ \\
\hline WROCc & 23 May 2016 & NOW $^{1}$ & LEICA & GR25 & $3.22 / 6.522$ & $12.1 \pm 10.1$ & $-62.4 \pm 2.0$ & $72.0 \pm 9.2$ & $-14.3 \pm 27.2$ \\
\hline WTZ3a & 25 October 2015 & 23 April 2016 & JAVAD & TRE_G3TH DELTA & 3.6.1b1-68-7da 1 & $-16.2 \pm 1.6$ & $20.4 \pm 2.6$ & & \\
\hline WTZ3b & 28 April 2016 & 12 January 2017 & JAVAD & TRE_G3TH DELTA & 3.6.1b1-68-7da1 & $-19.9 \pm 0.7$ & $19.4 \pm 5.1$ & & \\
\hline WTZ3b & 12 January 2017 & NOW $^{1}$ & JAVAD & TRE_G3TH DELTA & 3.6 .9 & $-19.9 \pm 0.7$ & $19.4 \pm 5.1$ & & \\
\hline WTZZa & 1 January 2014 & 17 April 2014 & JAVAD & TRE_G3TH DELTA & 3.5.3 19 September 2013 & $-14.5 \pm 1.7$ & & $169.7 \pm 9.4$ & \\
\hline WTZZa & 17 April 2014 & 14 August 2014 & JAVAD & TRE_G3TH DELTA & 3.5.5 3 March 2014 & $-14.5 \pm 1.7$ & & $169.7 \pm 9.4$ & \\
\hline WTZZa & 14 August 2014 & 27 January 2015 & JAVAD & TRE_G3TH DELTA & 3.6.0 23 June 2014 & $-14.5 \pm 1.7$ & & $169.7 \pm 9.4$ & \\
\hline WTZZa & 27 January 2015 & 16 June 2015 & JAVAD & TRE_G3TH DELTA & 3.6.1 30 December 2014 & $-14.5 \pm 1.7$ & & $169.7 \pm 9.4$ & \\
\hline WTZZa & 16 June 2015 & 12 July 2015 & JAVAD & TRE_G3TH DELTA & 3.6.2 8 April 2015 & $-14.5 \pm 1.7$ & & $169.7 \pm 9.4$ & \\
\hline WTZZb & 13 July 2015 & 20 November 2015 & JAVAD & TRE_G3TH DELTA & 3.6.28 April 2015 & $-16.3 \pm 0.8$ & $-130.2 \pm 3.0$ & & \\
\hline WTZZb & 20 November 2015 & 26 November 2015 & JAVAD & TRE_G3TH DELTA & 3.6.31 July 2015 & $-16.3 \pm 0.8$ & $-130.2 \pm 3.0$ & & \\
\hline WTZZb & 26 November 2015 & 16 February 2016 & JAVAD & TRE_G3TH DELTA & 3.6.4B1-57-AB7E & $-16.3 \pm 0.8$ & $-130.2 \pm 3.0$ & & \\
\hline WTZZc & 16 February 2016 & 19 May 2016 & JAVAD & TRE_G3TH DELTA & 3.6.4 12 January 2016 & $-12.2 \pm 1.0$ & $-133.7 \pm 0.8$ & & \\
\hline WTZZd & 19 May 2016 & 1 December 2016 & JAVAD & TRE_G3TH DELTA & 3.6.6 27 April 2016 & $-15.3 \pm 0.6$ & $-2.6 \pm 3.3$ & $22.2 \pm 0.0$ & \\
\hline WTZZe & 2 December 2016 & 12 January 2017 & JAVAD & TRE_G3TH DELTA & 3.6.6 27 April 2016 & $-12.7 \pm 0.8$ & $-6.0 \pm 1.2$ & $18.0 \pm 1.9$ & \\
\hline WTZZf & 12 January 2017 & 14 February 2017 & JAVAD & TRE_G3TH DELTA & 3.6.9 28 November 2016 & $-16.2 \pm 0.6$ & $-3.1 \pm 0.8$ & $17.5 \pm 0.0$ & \\
\hline WTZZg & 15 February 2017 & NOW $^{1}$ & JAVAD & TRE_G3TH DELTA & 3.6.9 28 November 2016 & $-12.3 \pm 0.8$ & $-6.5 \pm 1.3$ & $17.4 \pm 3.0$ & \\
\hline ZIMJa & 1 January 2014 & 12 May 2016 & JAVAD & TRE_G3TH DELTA & 3.4.918 April 2013 & $-20.6 \pm 1.9$ & $21.9 \pm 1.8$ & & \\
\hline ZIMJb & 12 May 2016 & NOW $^{1}$ & JAVAD & TRE_G3TH DELTA & 3.5.12 12 November 2015 & $-24.8 \pm 0.7$ & $19.3 \pm 2.8$ & & \\
\hline
\end{tabular}

${ }^{1}$ Calibration table is updated to 10 June 2017. 


\section{Conclusions}

In the present work a study of the accuracy of broadcast orbits has been presented, taking into account a time span of one week. In this phase, the offset between broadcast reference frames and ITRF has been evaluated, for homogeneous blocks of satellites. The results of an analysis carried out starting from 1 January 2014 and still active were presented, aimed at the evaluation of the misalignment between timescales of the various GNSS's. In the next sections the main results obtained are summarized and discussed.

\subsection{Reference Frames}

Reference frames adopted by GPS and Galileo FOC broadcast orbits, in the week taken into account, are aligned with ITRF since the translation of the origin is less than $0.10 \mathrm{~m}$ and rotations are less than 2 milliarcsec. For Galileo IOV, GLONASS and BeiDou instead translations at dm-level and rotations higher than 4 milliarcsec have been found.

The Galileo IOV broadcast reference frame is offset to ITRF by at most $0.23 \pm 0.04 \mathrm{~m}$ in Y.

The GLONASS M broadcast reference frame is offset to ITRF by at most $0.27 \pm 0.05 \mathrm{~m}$ in $\mathrm{Y}$ and the maximum rotation is $4 \pm 2$ milliarcsec about $Y$. The GLONASS K broadcast reference frame is offset to ITRF by at most $1.06 \pm 0.18 \mathrm{~m}$ in $\mathrm{Y}$ and the maximum rotation is $19 \pm 2$ milliarcsec about $\mathrm{X}$.

The BeiDou IGSO broadcast reference frame is offset to ITRF by at most $0.31 \pm 0.08 \mathrm{~m}$ in $\mathrm{Y}$ and the maximum rotation is $3.6 \pm 2.0$ milliarcsec about $Z$. BeiDou MEO broadcast reference frame is offset to ITRF by at most $0.38 \pm 0.35 \mathrm{~m}$ in $\mathrm{X}$ and the maximum rotation is $4.3 \pm 2.9$ milliarcsec about $\mathrm{Z}$.

\subsection{Coordinates and Clock Comparison}

In general coordinate and clock differences have been demonstrated to be discontinuous and show an oscillating trend with a period of about $12 \mathrm{~h}$ (except BeiDou IGSO satellites which have a period of about $24 \mathrm{~h}$ ). The discontinuities affect mostly the along-track component, in which they are about $1 \mathrm{~m}$ for GPS, Galileo and BeiDou IGSO and up to $3 \mathrm{~m}$ for GLONASS and BeiDou MEO, and to a lesser extent the radial and cross-track components, in which they are at dm-level.

GPS and Galileo broadcast ephemeris are closer to the precise orbits than those of GLONASS and BeiDou: for GPS and Galileo the average values of RMS are about $0.15 \mathrm{~m}$ and $1 \mathrm{~ns}$ whereas for GLONASS the average RMSs are $0.48 \mathrm{~m}$ and $5.6 \mathrm{~ns}$ and for BeiDou $0.43 \mathrm{~m}$ and $2.2 \mathrm{~ns}$.

\subsection{GNSS's Time Offsets}

GLONASS time scale was misaligned with respect to GPS by about -400 ns until the summer of 2014, when an alignment procedure started, according to [8]. This procedure was completed at the beginning of 2015, so currently the GLONASS timescale is aligned with GPS. Despite this the alignment is not constant, and there may be non-predictable variations with amplitude up to $100 \mathrm{ns,}$ like the one that happened in the second half of 2016.

BeiDou timescale is not aligned with GPS. The time offset vary continuously, with an oscillating trend and amplitude of about 70 ns. Furthermore it is not centered to zero, but it is always positive, although a slow trend of the average value to zero has been detected.

Galileo and QZSS time scales are aligned with GPS, although for Galileo two sudden variations, in November of 2015 and November-December of 2016, of about 60 and 30 ns, respectively, were noticed.

In addition to the previous constellation-specific considerations, for each time offset a receiver-dependent Inter System Bias (ISB) which could reach several tens of nanoseconds was evident. This bias tends to be almost constant in time, and so it could be calibrated. Since ISB is receiver-dependent, an upgrade of receiver firmware can change its amount and a new calibration is required.

The time offsets of 31 IGS/EUREF stations since 1 January 2014 were monitored. For each station, the potential discontinuities in time series of time offsets have been detected, and whenever possible the 
cause of discontinuity has been identified. Hence, for each continuity interval a relative-to-Septentrio calibration of time offsets has been evaluated.

Author Contributions: Luca Nicolini analyzed the data and wrote the paper; Alessandro Caporali conceived the model and supervised the work.

Conflicts of Interest: The authors declare no conflict of interest.

Appendix A

Comparison GPS IIR-A BROADCAST-CODE: week 1950 - $\max 5$

$\mathrm{I}=1.0 \mathrm{~m}$ or $2.5 \mathrm{~ns}$

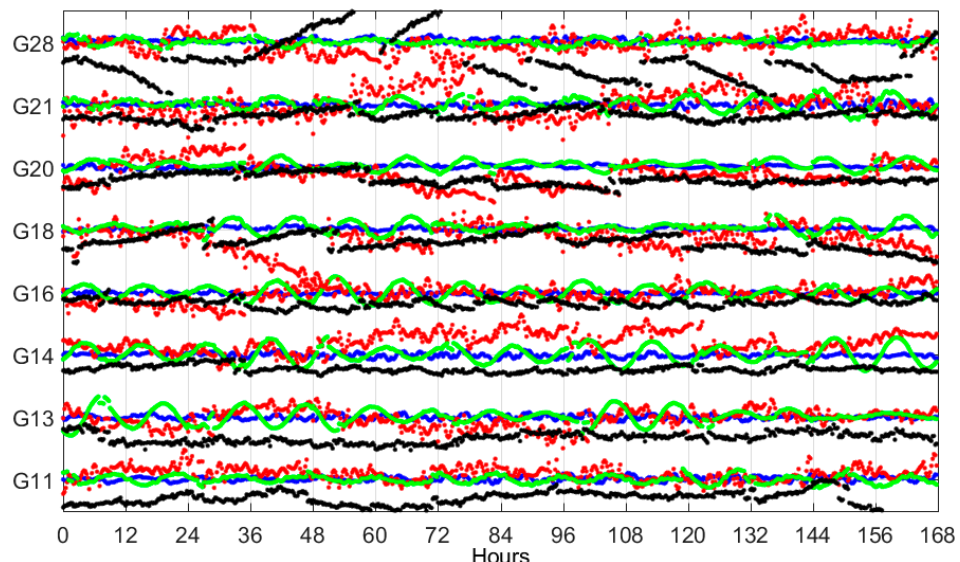

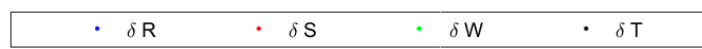

Comparison GPS IIR-BM BROADCAST-CODE: week 1950 - max 5

$\mathrm{I}=1.0 \mathrm{~m}$ or $2.5 \mathrm{~ns}$

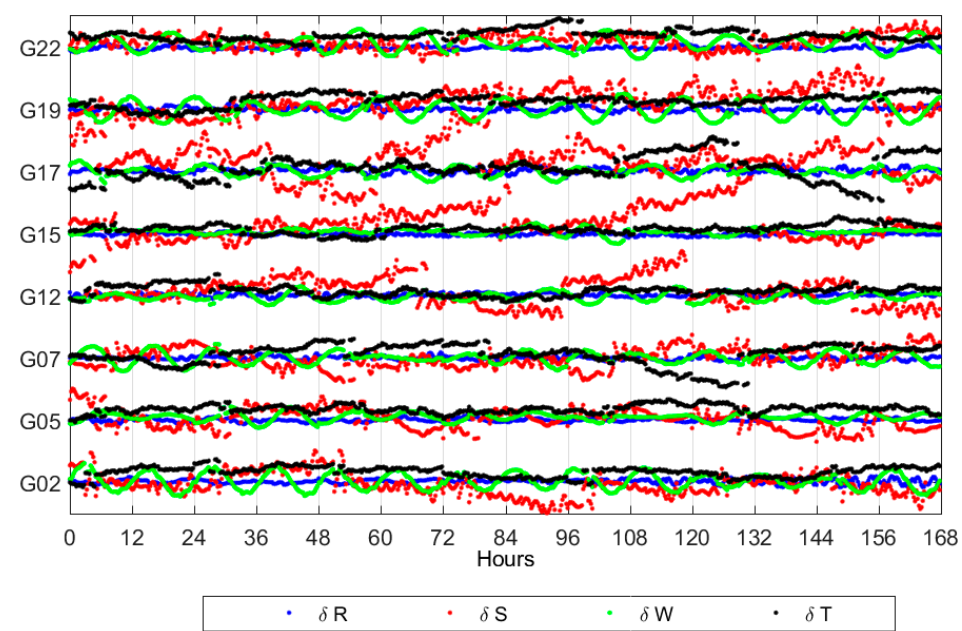

Comparison GPS IIR-BM BROADCAST-CODE: week 1950 - $\max 5$

I $=1.0 \mathrm{~m}$ or $2.5 \mathrm{~ns}$

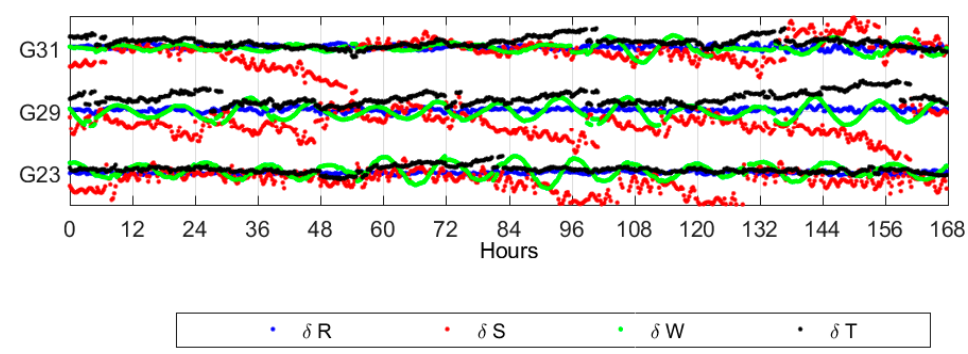

Figure A1. Cont. 
Comparison GPS IIF BROADCAST-CODE: week 1950 - max 5

$\mathrm{I}=1.0 \mathrm{~m}$ or $2.5 \mathrm{~ns}$

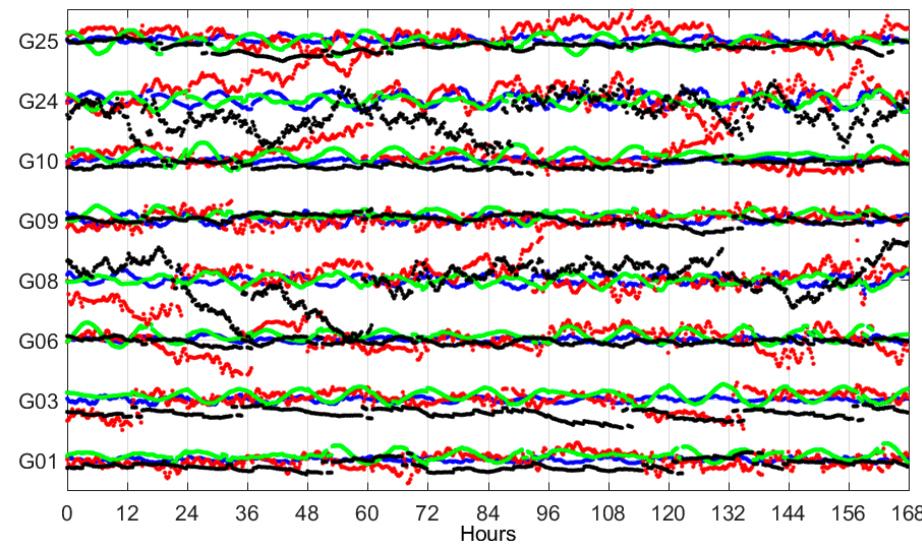

\begin{tabular}{|cccc|}
\hline$\cdot \delta R$ & $\cdot \delta S$ & $\delta \mathrm{W}$ & $\cdot \delta \mathrm{T}$ \\
\hline
\end{tabular} $l=1.0 \mathrm{~m}$ or $2.5 \mathrm{~ns}$

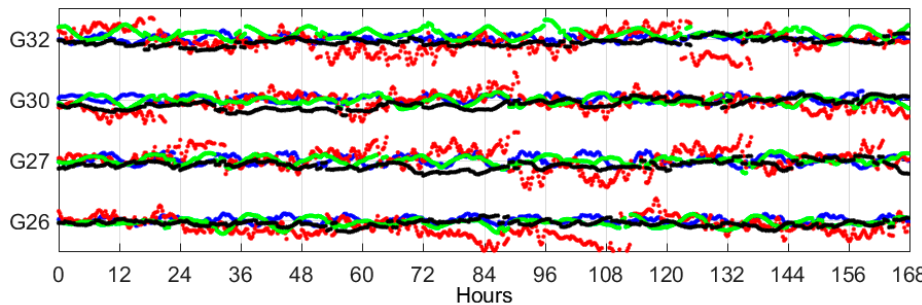

\begin{tabular}{|lllll}
\hline$\cdot \delta \mathrm{R}$ & $\cdot \delta \mathrm{S}$ & $\cdot \delta \mathrm{W}$ & $\cdot \delta \mathrm{T}$ \\
\hline
\end{tabular}

Figure A1. GPS coordinates and clock differences. "max 5" refers to the maximum threshold of $5 \mathrm{~m}$ as a condition for coordinate rejection.

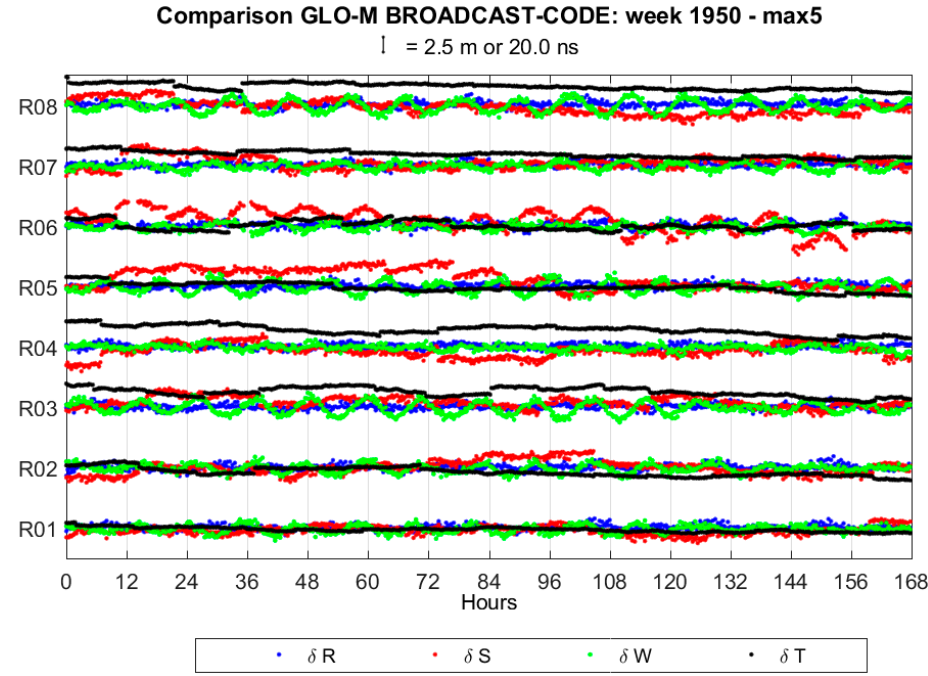

Figure A2. Cont. 


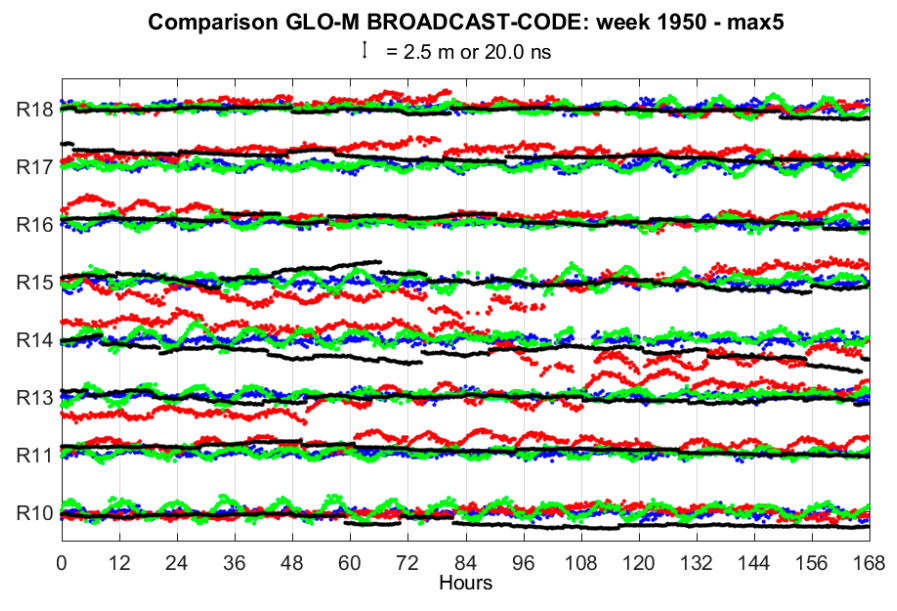

\begin{tabular}{|c|c|c|}
\hline$\cdot \delta R \quad \cdot \delta S$ & $\delta \mathrm{W}$ & $\cdot \delta T$ \\
Comparison GLO-M BROADCAST-CODE: week $1950-\max 5$
\end{tabular} $\mathrm{I}=2.5 \mathrm{~m}$ or $20.0 \mathrm{~ns}$
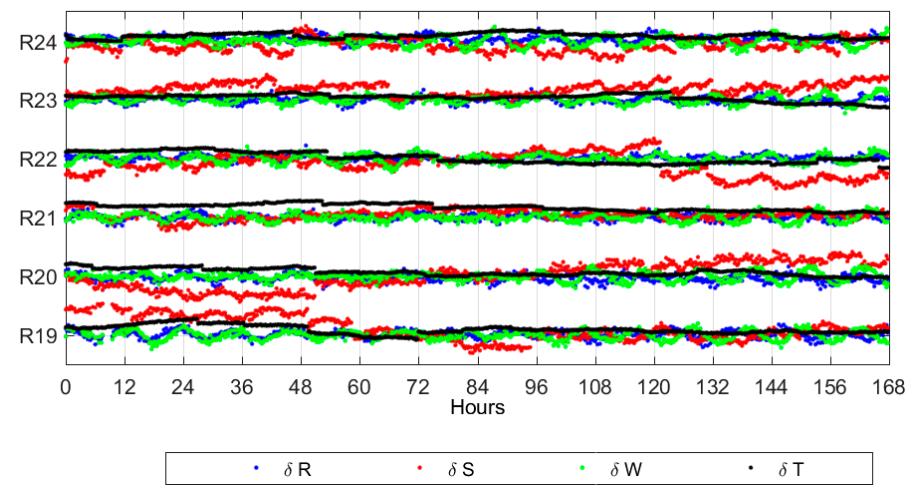

Comparison GLO-K BROADCAST-CODE: week 1950 - max5 I $=2.5 \mathrm{~m}$ or $20.0 \mathrm{~ns}$

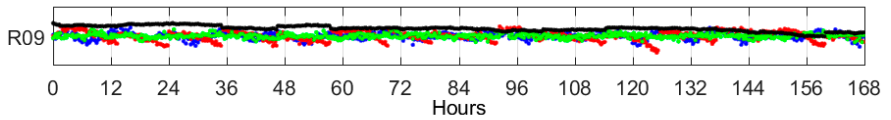

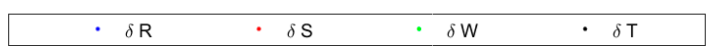

Figure A2. GLONASS coordinates and clock differences. "max 5" refers to the maximum threshold of $5 \mathrm{~m}$ as a condition for coordinate rejection.

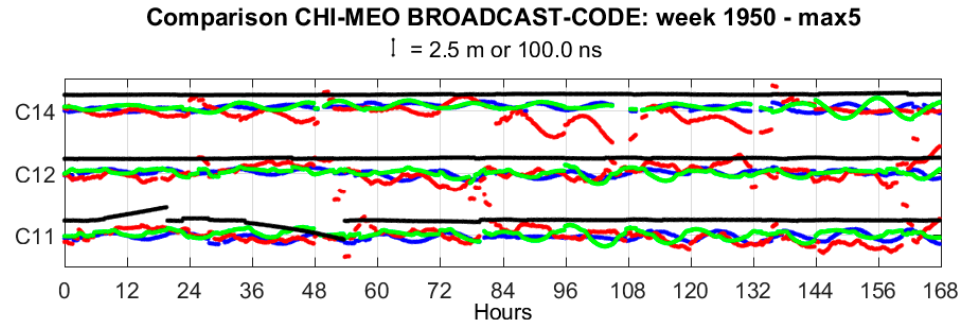

\begin{tabular}{|llll|}
\hline$\cdot \delta \mathrm{R}$ & $\cdot \delta \mathrm{S}$ & $\cdot \delta \mathrm{W}$ & $\cdot \delta \mathrm{T}$ \\
\hline
\end{tabular}

Figure A3. Cont. 


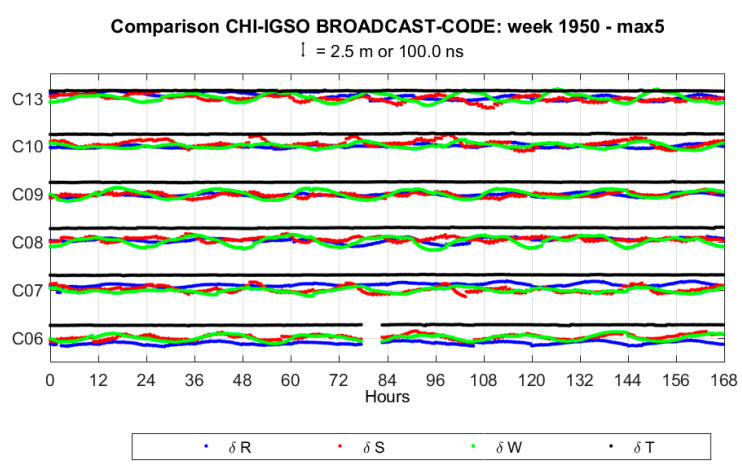

Figure A3. BeiDou coordinates and clock differences. "max 5" refers to the maximum threshold of $5 \mathrm{~m}$ as a condition for coordinate rejection.
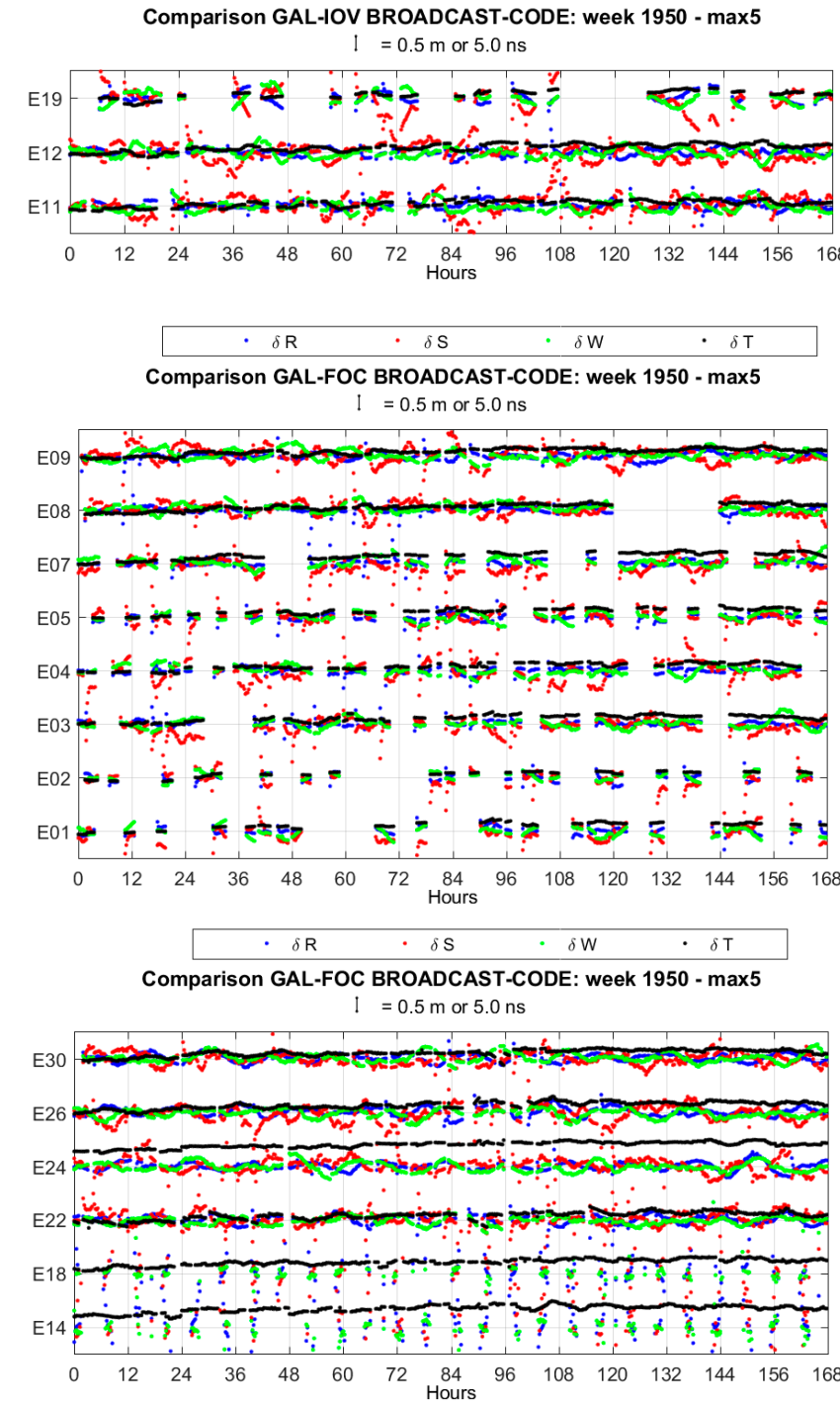

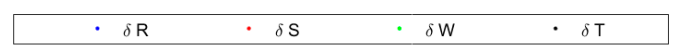

Figure A4. Galileo coordinates and clock differences. "max 5" refers to the maximum threshold of $5 \mathrm{~m}$ as a condition for coordinate rejection. 


\section{References}

1. The Multi-GNSS Experiment and Pilot Project (MGEX). Available online: http://mgex.igs.org (accessed on 29 September 2017).

2. EUREF Technical Working Group (TWG). Available online: www.euref.eu/euref_twg.html (accessed on 29 September 2017).

3. Montenbruck, O.; Steigenberger, P.; Hauschild, A. Broadcast versus precise ephemerides: A multi-GNSS perspective. GPS Solut. 2015, 19, 321-333. [CrossRef]

4. Dalla Torre, A.; Caporali, A. An analysis of intersystem biases for multi-GNSS positioning. GPS Solut. 2015, 19, 297-307. [CrossRef]

5. Caporali, A.; Nicolini, L. Interoperability of the GNSS's for Positioning and Timing. In New Advanced GNSS and 3D Spatial Techniques; Lecture Notes in Geoinformation and Cartography; Cefalo, R., Zielinski, J., Barbarella, M., Eds.; Springer: Cham, Switzerland, 2017; pp. 73-85, ISBN 978-3-319-56218-6.

6. Prange, L.; Orliac, E.; Dach, R.; Arnold, D.; Beutler, G.; Schaer, S.; Jäggi, A. CODE's five-system orbit and clock solution-The challenges of multi-GNSS data analysis. J. Geod. 2017, 91, 345-360. [CrossRef]

7. Revnivykh, S. GLONASS ground control segment: Orbit, clock, time scale and geodesy definition. In Proceedings of the 25th International Technical Meeting of the Satellite Division of the Institute of Navigation (ION GNSS 2012), Nashville, TN, USA, 17-21 September 2012; pp. 3931-3949.

8. Kosenko, V. Global Navigation Satellite System (GLONASS): Status and Development. In United Nations/Russian Federation Workshop on the Applications of Global Navigation Satellite Systems; Russian Federation: Krasnoyarsk, Russia, 2015.

9. Teunissen, P.J.G.; Montenbruck, O. Springer Handbook of Global Navigation Satellite Systems, 1st ed.; Springer International Publishing: Cham, Switzerland, 2017; ISBN 978-3-319-42926-7.

10. Dach, R.; Lutz, S.; Walser, P.; Fridez, P. Bernese GNSS Software Version 5.2. User Manual; University of Bern, Bern Open Publishing: Bern, Switzerland, 2015; ISBN 978-3-906813-05-9.

11. EU. European GNSS (Galileo) Open Service Signal in Space Interface Control Document. Available online: https:/ / www.gsc-europa.eu/system/files/galileo_documents/Galileo-OS-SIS-ICD.pdf (accessed on 4 January 2018).

12. Steigenberger, P.; Montenbruck, O. Galileo status: Orbits, clocks, and positioning. GPS Solut. 2017, 21, 319-331. [CrossRef]

13. International GNSS Service (IGS) RINEX Working Group and Radio Technical Commission for Maritime Services Special Committee 104 (RTCM-SC104). RINEX The Receiver Independent Exchange Format; Version 3.03; Werner Gurtner, Astronomical Institute of the University of Bern, Switzerland and Lou Estey, UNAVCO: Boulder, CO, USA, 2015.

14. Nischan, T. GFZRNX-RINEX GNSS Data Conversion and Manipulation Toolbox (Version 1.05). Available online: http:/ / dataservices.gfz-potsdam.de/panmetaworks/showshort.php?id=escidoc:1577894 (accessed on 4 January 2018).

15. Russian Institute of Space Device Engineering (RISDE). Global Navigation Satellite System GLONASS-Interface Control Document; Version 5.1; Russian Institute of Space Device Engineering: Moscow, Russia, 2008.

16. Håkansson, M.; Jensen, A.B.O.; Horemuz, M.; Hedling, G. Review of code and phase biases in multi-GNSS positioning. GPS Solut. 2017, 21, 849-860. [CrossRef]

17. Zeng, A.; Yang, Y.; Ming, F.; Jing, Y. BDS-GPS inter-system bias of code observation and its preliminary analysis. GPS Solut. 2017, 21, 1417-1425. [CrossRef]

18. Jiang, N.; Xu, Y.; Xu, T.; Xu, G.; Sun, Z.; Schuh, H. GPS/BDS short-term ISB modelling and prediction. GPS Solut. 2017, 21, 163-175. [CrossRef]

19. Odijk, D.; Teunissen, P.J.G. Characterization of between-receiver GPS-Galileo inter-system biases and their effect on mixed ambiguity resolution. GPS Solut. 2013, 17, 521-533. [CrossRef] 
20. Gioia, C.; Borio, D. A statistical characterization of the Galileo-to-GPS inter-system bias. J. Geod. 2016, 90, 1279-1291. [CrossRef]

21. Chen, J.; Xiao, P.; Zhang, Y.; Wu, B. GPS/GLONASS System Bias Estimation and Application in GPS/GLONASS Combined Positioning. In China Satellite Navigation Conference (CSNC) 2013 Proceedings. Lecture Notes in Electrical Engineering; Sun, J., Jiao, W., Wu, H., Shi, C., Eds.; Springer: Berlin/Heidelberg, Germany, 2013; pp. 323-333, ISBN 978-3-642-37403-6. 